\title{
Understanding the Electronic Interactions, Vertical Excitation Analysis, and the Photovoltaic Properties of 5-(2-ethylhexyl)-1,3-di(furan-2-yl)-4H-thieno[3,4- c]pyrrole-4,6-dione
}

Obieze Christian Enudi ( $\nabla$ enudij@gmail.com )

University of Calabar https://orcid.org/0000-0001-6306-2047

Hitler Louis

University of Calabar

Goodness J. Ogunwale

University of Ibadan

Michael T. Kadiri

University of Ibadan

Prince M. Okibe

University of Ibadan

Isaiah A. Adejoro

University of Ibadan

Terkumbur E. Gber

University of Calabar

Anthony M.S. Pembere

Jaramogi Oginga Odinga University of Science and Technology

Adedotun E. Adewale

University of Ibadan

Research Article

Keywords: D-A-D, spectroscopy, excitations, photovoltaic, DFT

Posted Date: October 22nd, 2021

DOI: https://doi.org/10.21203/rs.3.rs-978991/v1

License: (c) (i) This work is licensed under a Creative Commons Attribution 4.0 International License.

Read Full License 


\title{
Understanding the electronic interactions, vertical excitation analysis, and the photovoltaic properties of 5-(2-ethylhexyl)-1,3-di(furan-2-yl)-4H-thieno[3,4- c]pyrrole-4,6-dione
}

\author{
Obieze C. Enudi ${ }^{1,2,3 *}$, Hitler Louis ${ }^{1,2 *}$, Goodness J. Ogunwale ${ }^{3}$, Michael T. Kadiri ${ }^{3}$, Prince M. \\ Okibe $^{3}$, Isaiah A. Adejoro ${ }^{3}$, Terkumbur E. Gber ${ }^{1,2}$, Anthony M.S. Pembere ${ }^{4}$, and Adedotun E. \\ Adewale $^{3}$ \\ ${ }^{1}$ Computational and Bio-simulation Research Group, University of Calabar, Calabar, Nigeria \\ ${ }^{2}$ Department of Pure and Applied Chemistry, Faculty of Physical Sciences, University of Calabar, \\ Calabar, Nigeria. \\ ${ }^{3}$ Department of Chemistry, Faculty of Sciences, University of Ibadan, Ibadan, Nigeria. \\ ${ }^{4}$ Department of Physical Sciences, Jaramogi Oginga Odinga University of Science and Technology, \\ Bondo, Kenya
}

*Corresponding author's email; enudij@gmail.com; and louismuzong@gmail.com

\begin{abstract}
Organic photovoltaic (OPV) are a promising new class of photovoltaic as they offer several advantageous features including large surface area to volume ratio, low cost, lightweight properties, and durability. The limitation of OPV that prevented their adoption for use in the past was their low power conversion efficiency (PCE) but that drawback has been solved by the development of the donor-acceptor-donor (DA-D) system with high conversion efficiencies. Herein, 5-(2-ethylhexyl)-1,3-di (furan-2-yl)-4H-thieno [3,4-c]pyrrole-4,6(5H)-dione (FTPF), a donor-acceptor-donor monomer was investigated for its optoelectronic, excited state, and photovoltaic properties using a density functional theory (DFT) and time-dependent density function theory (TD-DFT) at the B3LYP/6-31+G(d,p) theoretical method. The spectral analysis (FT-IR, UV-vis, and NMR), electronic molecular properties, natural bonding orbitals (MOs and NBOs) analyses, and excitation were studied at this level in gas, hexane, DMF, and THF. The UV-Vis spectrum showed that FTPF exhibited mono-absorption in non-polar gas and hexane, but dual absorptions in polar solvents (DMF and THF) having maximum wavelength $\left(\lambda_{\max }\right)$ at $351,359,371$ and $373 \mathrm{~nm}$ in gas, hexane, THF, and DMF respectively, showing a major red shift as solvent became polar. The hole-electron excitation studies of the first five singlet states: $S_{0} \rightarrow S_{1} / S_{2} / S_{3} / S_{4} / S_{5}$ in gas and DMF phases showed that $S_{0} \rightarrow S_{I}$ is a delocalized $\pi \rightarrow \pi^{*}$ Rydberg excitations originating from the D-A-D C=C $\pi$ bonds, $S_{0} \rightarrow S_{2}$ is $\pi \rightarrow \pi^{*}$ local excitation, while $S_{0} \rightarrow S_{3}$ in water occurred as an $n \rightarrow \pi^{*}$ from the carbonyl and
\end{abstract}


azolide groups of the acceptor unit, but $n \rightarrow \pi^{*}$ charge transfer (CT) in DMF. The $S_{0} \rightarrow S_{5}$ in water and $S_{0} \rightarrow S_{4}$ are $\mathrm{n} \rightarrow \pi^{*}$ LE type excitations, while $S_{0} \rightarrow S_{5}$ in DMF conformed to a delocalized $\pi \rightarrow \pi^{*}$ excitation extended over the D-A-D conjugated backbone. FTPF provided efficient electron injection in all studied solvent; showing that FTPF is a sure-bet for opto-electronic application.

Keywords: D-A-D; spectroscopy; excitations; photovoltaic; DFT

\subsection{Introduction}

Photovoltaics (PVs) are used in solar cells to convert optical energy into electrical energy for various applications [1-8]. Typically, inorganic semiconductors like crystalline silicon are used as photovoltaics in solar cells but they are costly and suffer from efficiency limitations [1, 9-12]. Organic photovoltaics (OPVs) are a promising new class of photovoltaics as they offer several advantageous features including large surface area to volume ratio, low cost, lightweight properties and durability [13-18]. OPVs can even be made up to 1000 times thinner than crystalline silicon photovoltaics offering significant savings on materials needed [14,18]. The limitation of OPVs that prevented their adoption for use in the past was their low conversion efficiency (CE) but that drawback has been solved by the development of the donoracceptor-donor (D-A-D) system with their high conversion efficiencies [14, 19-20]. The D-A-D systems are classified by high conjugated bonding systems which allow strong electronic transitions. Dyes are other category of organic materials applied in photovoltaics, due to their high $\pi$-electron conjugations, leading to great electronic excitations and transitions [21-23]. These systems are characterized with low HOMO/LUMO energy gap, which gives insight into why these molecules act as semiconductors [24]. Studying highly conjugated systems in order to understand their properties and to improve their energy conversions and hence applicability is crucial in the optical and electronic industries [25-28]. Density functional theory (DFT) is a very reliable theory for predicting the density of electrons around a molecule thereby enabling easy simulation and prediction of that molecule's reactions and behaviour under certain conditions with high level of accuracy [29-34]. DFT and other computational chemistry methods are employed in independent studies of molecules systems or also as a validating study premise for experimentally studied chemical interactions [29, 30, 34].

A D-A-D system is usually a polymer in which its repeating monomer is made up of an acceptor unit (A), sandwiched between two donor units (D) [31, 35-36]. Examples of donor units are thiophene (T), selenophene (S) and furan or their structural derivatives. The D-A-D systems have proven themselves essential in the development of organic photovoltaics and so it will be necessary to carry out studies on them in order to predict their optoelectronic behaviour [35-37]. Çakal et al, on their journey to understanding the effect of D units on the opto-electrical characteristics of a monomer and subsequently the polymer, achieved the synthesis and characterization of 5-(2-ethylhexyl)-1,3-di (furan-2-yl)-4H-thieno 
[3,4-c]pyrrole-4,6(5H)-dione (FTPF) and 5-(2-ethylhexyl)-1,3-di (selenophen-2-yl)-4H-thieno [3,4c]pyrrole-4,6(5H)-dione (STPS), which are furanyl and selenophenyl based D-A-D systems, respectively [35]. They reported the absorption UV excitation behaviour of FTPF in dichloromethane (DCM), and its emission spectroscopic characteristics in hexane, THF and DMF, highlighting the solvent effect on the spectral properties.

In order understand the electronic interactions within the D-A-D system of FTPF and to further explore other informative optoelectronic and photovoltaic properties of their conjugated $\pi$-electron system, we employed the DFT method of investigation to perform theoretical calculations on FTPF (Fig. 1.). The UV-Vis spectral determination is conducted in gas, hexane, THF and DMF while the other spectral properties (FT-IR and NMR) was analyzed in gas phase to obtain data necessary for characterization and structure determination. Potential energy distribution (PED) analysis was performed to achieve the FT-IR absorption parameters [38-39]. Other electronic property determinations like natural bonding orbital (NBO) analysis [40] and vertical excitation analysis of the first 5 excitations of FTPF are also pivotal in this study, so as to register the important intra-monomer, hence polymeric electronic transitions of our titled molecule [21-23]. The electronic excitations and oscillator strength parameters obtained from the UV-vis calculations were employed for the investigation of the photovoltaic properties. The structure of 5-(2-ethylhexyl)-1,3-di (furan-2-yl)-4H-thieno [3,4-c]pyrrole-4,6(5H)-dione is shown in Fig. 1.

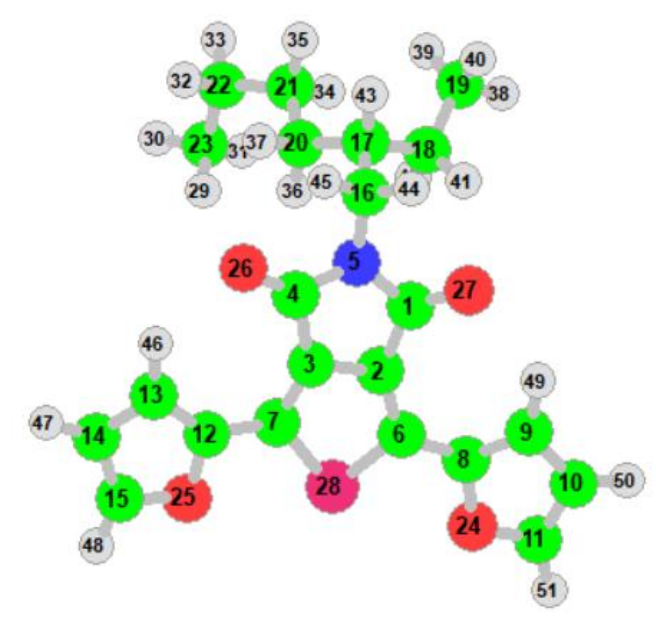

Fig. 1. Optimized Structure of 5-(2-ethylhexyl)-1,3-di(furan-2-yl)-4H-thieno[3,4-c]pyrrole-4,6-dione (FTPF). 


\subsection{Computational details}

The density functional theory (DFT) computational method is an appropriate theoretical approach to studying the optical and spectral properties of highly conjugated systems (e.g. natural dyes, D-A-D systems), owing to its swiftness and accuracy in dynamic electron correlation recovery [21, 41-42]. The ground state geometry optimization of the 5-(2-ethylhexyl)-1,3-di(furan-2-yl)-4H-thieno[3,4-c]pyrrole4,6-dione (FTPF); a donor-acceptor-donor monomer was conducted at the DFT/B3LYP theoretical method using $6-31+\mathrm{G}$ (d, p) basis set $[43,44]$ in gas, hexane, tetrahydrofuran (THF) and dimethylformamide (DMF) solvents using Gaussian09W and GaussView 6.0.16 packages [45]. For vertical excitation energy and photovoltaic property determinations, a single point energy calculations using the TD-SCF/CAM-B3LYP/6-31+G $(\mathrm{d}, \mathrm{p})$ time-dependent density functional calculations was carried out for the initial 5 singlet vertical excitation states in gas and all the studied solvents. Scanning tunneling microscopy (STM) images, computed UV-vis spectrum in different solvents, density of state (DOS) plots and atomic dipole corrected Hirshfield (ADCH) atomic charges were all analyzed using the Multiwfn 3.7 (dev) function program [46] (freely obtainable from http://sobereva.com/multiwfn). The frontier molecular orbital (FMO) isosurfaces, molecular electrostatic potential (MEP) maps and natural bonding orbital (NBO) analyses were conducted on in-built Gaussian 3.1 method available in Gaussian 09W programme [45]. NBO analysis was carried out to determine the second perturbation energies of all energy stabilizing donor-acceptor orbital interactions of filled donor and virtual acceptor molecular orbitals. Potential energy distribution (PED) analysis were performed on Vibrational Energy Distribution Analysis (VEDA) 4 software [47] to form the basis of elucidation of IR spectrum of FTPF.

Excitation determinant indices $\left(S_{r}, D, H, t\right.$, hole delocalization and electron delocalization) were calculated for the first 5 excitations to ascertain the spatial distributions of hole and electron on FTPF. Excitations are classified as charge transfer (CT), Rydberg or local excitations (LE) depending on the spatial distribution, overlapping extent, centroid position, etc. which are deduced from the various indices considered in this work [23]. Calculations for the various indices in this excitation study were done using equations from Le Bahers et al. (2011) [48]. The extent of overlap between hole and electron in a molecular system is defined by $\mathrm{Sr}$ index. $\mathrm{Sr}$ can be obtained using equation 1 .

$S_{\mathrm{r}}$ index $=\int S_{r}(r) \mathrm{dr}=\int \sqrt{\rho^{\text {hole }}(r) \rho^{\text {ele }}(r) d r}$

Where $r$ is vector component with respect to position, $\rho^{\text {hole }}$ and $\rho^{\text {ele }}$ are the hole and electron densities, respectively. The most significant position of either hole and electron distribution in the $\mathrm{x}, \mathrm{y}$ or $\mathrm{z}$ coordinate is defined by the centroid to the coordinate under consideration. For example, the $\mathrm{X}$ coordinate of centroid of hole is written in equation 2.

$X_{\text {ele }}=\int \mathrm{x} \rho^{\text {hole }}(\mathrm{r}) \mathrm{dr}$ 
Where $\mathrm{x}$ is the $\mathrm{X}$ component of vector, $\mathrm{r}$ with respect to position.

The spatial separation of the centroids of hole from electron (i.e. $\mathrm{C}_{\text {hole }}$ from $\mathrm{C}_{\text {ele }}$ ) is defined by the $\mathrm{D}$ index which is deduced by invoking equations 3 to 6 . This defines the net charge transfer length magnitude. The extend of charge transfer is obtained from the $\mathrm{D}$ values for the various coordinates. Considering $\mathrm{x}, \mathrm{y}$ and $\mathrm{z}$ coordinates, $\mathrm{D}$ is given by equations 3,4 and 5, respectively.

$D_{\mathrm{x}}=\left|\mathrm{X}_{\text {ele }}-\mathrm{X}_{\text {hole }}\right|$

$D_{\mathrm{y}}=\left|\mathrm{Y}_{\text {ele }}-\mathrm{Y}_{\text {hole }}\right|$

$D_{\mathrm{z}}=\left|\mathrm{Z}_{\text {ele }}-\mathrm{Z}_{\text {hole }}\right|$

$D$ index $=\sqrt{(D x)^{2}+(D y)^{2}+(D z)^{2}}$

t index is the mean difference between $H$ in CT direction from $D$ index. The degree of separation of hole and electron in $\mathrm{CT}$ direction is defined by the $\mathrm{t}$ index. $\mathrm{H}$ index, which is the overall measure of spatial extension of hole and electron distribution. $\mathrm{H}$ index is deduced from the root mean square distribution of electron $\left(\left|\sigma_{\text {ele }}\right|\right)$ and hole $\left(\left|\sigma_{\text {hole }}\right|\right)$, using equation 7.

$H$ index $=\left(\left|\sigma_{\text {hole }}\right|+\left|\sigma_{\text {ele }}\right|\right) / 2$

The hole delocalization index (HDI) and electron delocalization index (EDI) are electron density dependent parameters, and are important in explaining the type of excitation occurring in a conjugated system. Equations 8 and 9 are used to determine HDI and EDI.

$H D I=100 \times \sqrt{\int\left[\rho^{\text {hole }}(r)\right]^{2} d r}$

$E D I=100 \times \sqrt{\int\left[\rho^{e l e}(r)\right]^{2} d r}$ 


\subsection{RESULTS AND DISCUSSIONS}

\subsection{Spectroscopic and Geometrical Properties}

We carried out UV-Vis spectroscopic calculations of FTPF using Gaussian09W in gas, DMF, hexane and THF solvents in order to investigate the effect of these solvents on maximum wavelength $\left(\lambda_{\max }\right)$ of the electronic absorption transitions. The ${ }^{1} \mathrm{H}-\mathrm{NMR}$ and ${ }^{13} \mathrm{C}-\mathrm{NMR}$ calculations were performed to determine the chemical shifts values for hydrogen and carbon atoms in the FTPF monomer unit [49,50]. A combined UV-Vis spectrum of FTPF monomer in the various considered solvents was plotted using Multiwfn programme for clear visualization. Also, potential energy distribution (PED) assignments for the various IR vibrations were conducted on VEDA software [47], in order to understand the different interatomic vibrations of the studied D-A-D molecule.

\subsubsection{UV-Visible analysis}

In this study, we considered the effect of three solvents on the UV-Vis spectrum obtained in gas phase. A non-polar hexane and aprotic polar DMF and THF were added to solvate FTPF to achieve the maximum wavelenght of absorption. The combined computational UV-Vis spectrum of FTPF can be visualized in Fig. 2., for a clear understanding and correlation of the contributions of various solvents on the optoelectronic behaviour of FTPF.

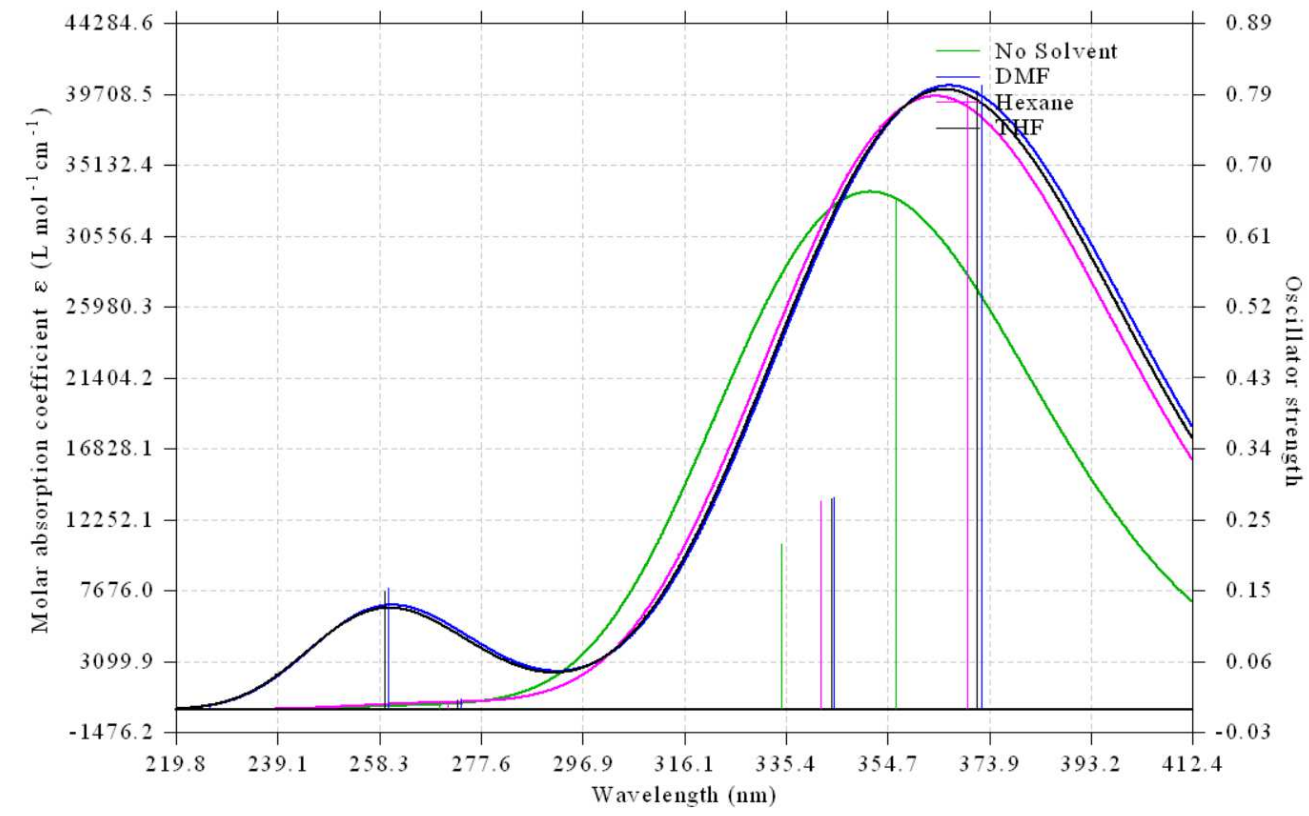

Fig. 2. Computational UV-Vis spectrum of FTPF in gas, hexane, DMF and THF, calculated with CAMB3LYP method at 6-31+G(d,p) basis set. 
Dual absorption peaks were recorded for FTPF in DMF and THF, which is characteristic of two different allowed transitions in a conjugated system [51,52]. The peak corresponding to a high energy absorption occurred at $261 \mathrm{~nm}$ in DMF and $263 \mathrm{~nm}$ in THF nm $\left(\pi \rightarrow \pi^{*}\right.$ transition), while the $\mathrm{n} \rightarrow \pi^{*}$ transition occurred at $373 \mathrm{~nm}$ in DMF and 371 in THF (lower energy transition, traceable to intramolecular charge transfer (ICT) between D and A units) [35]. Both absorptions exhibit equivalent intensities, showing that both solvents have significantly similar effect on the optical properties of our studied molecule. From the $\lambda_{\max }$ of absorption values in the different solvents $(351 \mathrm{~nm}$ in gas, $359 \mathrm{~nm}$ in hexane, $371 \mathrm{~nm}$ in THF and $373 \mathrm{~nm}$ in DMF), one can observe a significant red shift from non-polar to polar solvents. Hexane posed an ignorable shift effect on the system.

\subsubsection{Infrared Vibrational Studies}

Every molecule responds to IR light through signatory interatomic vibrations whose frequencies depend on the nature of bonds (different functional groups) and the modes of vibration is determined by the number of atoms in the molecule and spatial arrangement of the molecule. For a non-linear system like FTPF, the number of vibrations is given by equation 10, where $\mathrm{N}$ is the total number of atoms in the molecule [51,52]. The potential energy distribution (PED) assignments for the various frequencies of vibrational were generated for FTPF at B3LYP/6-31+G(d,p) levels.

Number of vibrational modes $=3 \mathrm{~N}+6$

Results for the PED assignments (in \%) for IR vibrational frequencies are reported on Table 1. Selected important vibrations are discussed in this manuscript paying more attention to the two donors and the acceptor units. The IR spectrum from our studies on FTPF is shown in Fig. S1., of the supplementary information.

Table 1. PED Assignment for IR vibrational frequencies of FTPF calculated with CAM-B3LYP method at $6-31+G(d, p)$ basis set.

\begin{tabular}{|c|c|}
\hline Frequency $\left(\mathrm{cm}^{-1}\right)$ & Assignment of PED (\%) \\
\hline 3299.92 & $11 v \mathrm{CH}+85 v \mathrm{CH}$ \\
\hline 3278.80 & $80 v \mathrm{CH}+11 v \mathrm{CH}$ \\
\hline 3278.53 & $79 v \mathrm{CH}+12 v \mathrm{CH}$ \\
\hline 3265.65 & $16 v$ asy $\mathrm{CH}+72 v \mathrm{CH}$ \\
\hline $3265 . .46$ & $14 v \mathrm{CH}+73 v \mathrm{CH}$ \\
\hline 3123.10 & $96 v$ asy $\mathrm{CH}$ \\
\hline 3109.08 & $81 v$ asy $\mathrm{CH}+10 v$ asy $\mathrm{CH}$ \\
\hline 3096.90 & $84 v \mathrm{CH}$ \\
\hline 3078.93 & $83 v$ asy $\mathrm{CH}$ \\
\hline 2992.15 & $96 \vee \mathrm{CH}$ \\
\hline 1788.50 & $80 \vee(\mathrm{C}=\mathrm{O})$ \\
\hline 1747.15 & $85 v$ asy $(\mathrm{C}=\mathrm{O})$ \\
\hline
\end{tabular}




\begin{tabular}{ll}
\hline 1623.58 & $75 v(\mathrm{C}=\mathrm{C})$ \\
1617.25 & $78 v(\mathrm{C}=\mathrm{C})$ \\
1585.58 & $62 v$ asy $(\mathrm{C}=\mathrm{C})$ \\
1517.81 & $62 \beta \mathrm{HCH}$ \\
1517.61 & $61 v(\mathrm{C}=\mathrm{C})+16 \beta$ asy $(\mathrm{HCO})$ \\
1512.73 & $66 \beta$ asy $(\mathrm{HCH})+11 \tau(\mathrm{HCCC})$ \\
1510.05 & $49 \beta(\mathrm{HCH})+10 \beta(\mathrm{HCH})$ \\
1506.56 & $63 v(\mathrm{C}=\mathrm{C})+16 \beta(\mathrm{HCO})$ \\
1504.72 & $69 \beta(\mathrm{HCH})+11 \tau(\mathrm{HCCC})$ \\
1430.09 & $14 v$ asy $(\mathrm{C}-\mathrm{C})+10 \beta(\mathrm{HCO})+17 \beta(\mathrm{C}-\mathrm{O}-\mathrm{C})$ \\
1425.64 & $14 \tau(\mathrm{HCNC})+14 \tau(\mathrm{HCCC})$ \\
1395.69 & $14 \beta(\mathrm{HCN})+12 \beta$ asy $(\mathrm{HCC})+10 \tau(\mathrm{HCCH})$ \\
1383.93 & $17 v(\mathrm{CC})+12 \beta(\mathrm{HCC})+13 \tau$ asy $(\mathrm{HCNC})$ \\
1377.62 & $51 \tau$ asy $(\mathrm{HCCH})$ \\
1338.57 & $22 \beta(\mathrm{HCC})+10 \tau$ asy $(\mathrm{HCCC})+14 \tau(\mathrm{HCCC})$ \\
1329.54 & $11 \beta(\mathrm{HCN})+19 \beta(\mathrm{HCC})$ \\
1321.80 & $30 v(\mathrm{CC})+11 \beta(\mathrm{CCC})+15 \beta(\mathrm{HCC})$ \\
1275.38 & $14 \beta$ asy $(\mathrm{HCC})+11 \tau$ asy $(\mathrm{HCCC})+10 \tau(\mathrm{HCCC})$ \\
1187.65 & $11 v$ asy $(\mathrm{CC})+18 v(\mathrm{CH})+32 \beta$ asy $(\mathrm{HCO})$ \\
1124.01 & $10 v$ asy $(\mathrm{CC})+15 \tau$ asy $(\mathrm{HCCC})$ \\
1056.96 & $11 \tau$ asy $(\mathrm{HCCH})$ \\
1040.33 & $31 \beta(\mathrm{HCC})+14 \beta$ asy $(\mathrm{HCC})+10 \beta(\mathrm{COC})$ \\
1038.26 & $13 \beta$ asy $(\mathrm{HCC})+12 \beta(\mathrm{HCC})+14 \beta$ asy $(\mathrm{COC})$ \\
748.07 & $20 \tau$ asy $(\mathrm{HCOC})+37$ OP asy $(\mathrm{CCCC})$ \\
165.51 & $11 \beta(\mathrm{CCC})+14 \tau(\mathrm{CCCC})+11 \tau$ asy $(\mathrm{CNCC})$ \\
\hline
\end{tabular}

\subsubsection{C-H vibrations}

Saturated C-H stretching vibrations (both symmetric and asymmetric) occurred around 2900-2992.25$\mathrm{cm}^{-1}$, all are characteristic of the ethylhexyl substituent on the pyrroledione acceptor. Other $\mathrm{C}-\mathrm{H}$ stretching vibrations above $3000 \mathrm{~cm}^{-1}$ are for the $\mathrm{sp}^{2}$ hybridized $\mathrm{C}-\mathrm{H}$ bonds, notable are the vibrations at 3299.92, 3278.80, 3265.65 3123.10, $3109.08 \mathrm{~cm}^{-1}$ with PED (85, 80, 72, 96 and $81 \%$ ), respectively. Bending vibrations involving C-H linkages appeared between $1380-1500 \mathrm{~cm}^{-1}$. Some notable bending in FTPF at various frequencies are, $\mathrm{HCH} ; 1517.81 \mathrm{~cm}^{-1}$ (PED; 49 and 10), $1504.72 \mathrm{~cm}^{-1}$ (PED; 69), HCO; $1517.61 \mathrm{~cm}^{-1}$ (PED; 16), $1506.56 \mathrm{~cm}^{-1}$ (PED; 10), HCC; $1383.93 \mathrm{~cm}^{-1}$ (PED; 12), $1329.54 \mathrm{~cm}^{-1}$ (PED; 12), $\mathrm{HCN} ; 1395.69 \mathrm{~cm}^{-1}(\mathrm{PED} ; 14)$.

\subsubsection{C-C vibrations}

The C-C single bond stretching vibrations of FTPF occurred within the range 1124- $1390 \mathrm{~cm}^{-1}$, with all having relative low PED, a basic property of saturated C-C IR stretches of alkyl groups. Unsaturated $\mathrm{C}=\mathrm{C}$ stretching vibrations occurred at higher frequencies when compared to the saturated vibrations, which agrees to the theory that stronger bond exhibits vibration at higher frequencies [53]. Notable $\mathrm{C}=\mathrm{C}$ 
stretching vibrations are $1623.58 \mathrm{~cm}^{-1}$ (PED; 75), $1617.25 \mathrm{~cm}^{-1}$ (PED; 78), $1585.58 \mathrm{~cm}^{-1}$ (PED; 62). Other vibrations involving the $\mathrm{C}-\mathrm{C}$ bonds are seen in bends of $\mathrm{HCC}$ and $\mathrm{CCC}$, and the torsional vibrations involving $\mathrm{HCCC}, \mathrm{HCCH}, \mathrm{CCCC}, \mathrm{CNCC}$, etc., all occurring below $1530 \mathrm{~cm}^{-1}$.

\subsubsection{C-O vibrations}

Naturally, $\mathrm{C}=\mathrm{O}$ stretching vibrations occurs around $1600-1800 \mathrm{~cm}^{-1}$, the carbonyl stretching vibrations for FTPF occurred at the following frequencies; $1788.50 \mathrm{~cm}^{-1}$ (PED; 80), $1747.15 \mathrm{~cm}^{-1}$ (PED; 85), and $1623.58 \mathrm{~cm}^{-1}$ (PED; 75). Other vibrations involving $\mathrm{C}-\mathrm{O}$ bonds are the bending vibrations of $\mathrm{HCO}$; $1517.61 \mathrm{~cm}^{-1}$ (PED; 16), $1430.09 \mathrm{~cm}^{-1}$ (PED; 10), and $1187.65 \mathrm{~cm}^{-1}$ (PED; 32), COC; $1430.09 \mathrm{~cm}^{-1}$ (PED; 17), $1040.33 \mathrm{~cm}^{-1}$ (PED; 10), and also some torsional vibrations like; $748.07 \mathrm{~cm}^{-1}$ (PED; 20).

\subsubsection{C-N vibrations}

The N-H stretching vibrations are absent showing that there is no protonated nitrogen atom in FTPF molecule. Also, N-C stretching vibrations that occurred in FTPF are not significant, due to their ignorable PED. Notable bending and torsional vibrations involving $\mathrm{HCN}$ and $\mathrm{CNCC}$, occurred at $1329.54 \mathrm{~cm}^{-1}$ (PED; 11) and $165.51 \mathrm{~cm}^{-1}$ (PED; 11), respectively. C-S bond vibrations gave ignorable vibrations; hence they are exempted from our discussion.

\subsubsection{Nuclear Magnetic Resonance (NMR) Spectroscopy}

The chemical shift for the different protons and carbon atoms in FTPF corresponding to their level of interaction with external magnetic field or photons of radiofrequency were determine and the NMR spectrum plotted (Table 2, and Fig. S2). NMR data are very important especially in the diagnostic characterization of the compound [49].

Table 2. ${ }^{1} \mathrm{H}$ and ${ }^{13} \mathrm{CNMR}$ data for FTPF generated with CAM-B3LYP method at 6-31+G(d,p) basis set.

\begin{tabular}{cccccc}
\hline H atom & $\begin{array}{c}\text { Chemical Shift } \boldsymbol{\delta} \\
(\mathbf{p p m})\end{array}$ & $\begin{array}{c}\text { Atom } \\
\text { Specification }\end{array}$ & $\mathbf{C}$ atom & $\begin{array}{c}\text { Chemical Shift } \boldsymbol{\delta} \\
(\mathbf{p p m})\end{array}$ & $\begin{array}{c}\text { Atom } \\
\text { Specification }\end{array}$ \\
\hline $\mathrm{H}_{31}$ & 0.70 & $\mathrm{R}-\mathrm{CH}_{3}$ & $\mathrm{C}_{4}$ & 151.07 & $\mathrm{~N}-\mathrm{C}=\mathrm{O}$ \\
$\mathrm{H}_{40}$ & 1.17 & $\mathrm{R}-\mathrm{CH}_{3}$ & $\mathrm{C}_{1}$ & 150.68 & $\mathrm{~N}-\mathrm{C}=\mathrm{O}$ \\
$\mathrm{H}_{30}$ & 1.22 & $\mathrm{R}-\mathrm{CH}_{3}$ & $\mathrm{C}_{8}$ & 136.48 & $=\mathrm{C}-\mathrm{O}$ \\
$\mathrm{H}_{29,38,39} \& \mathrm{H}_{42}$ & 1.31 & $\mathrm{R}-\mathrm{CH}_{3}$ or $\mathrm{R}-\mathrm{CH}_{2}-\mathrm{R}$ & $\mathrm{C}_{12}$ & 136.18 & $=\mathrm{C}-\mathrm{O}$ \\
$\mathrm{H}_{34,32} \& \mathrm{H}_{43}$ & 1.63 & $\mathrm{R}-\mathrm{CH}_{2}-\mathrm{R}_{2}$ or $\mathrm{R}_{3} \mathrm{C}-\mathrm{H}$ & $\mathrm{C}_{15}$ & 129.42 & $=\mathrm{C}-\mathrm{O}$ \\
$\mathrm{H}_{35,36}$ & 1.73 & $\mathrm{R}-\mathrm{CH}_{2}-\mathrm{R}$ & $\mathrm{C}_{11}$ & 129.20 & $=\mathrm{C}-\mathrm{O}$ \\
$\mathrm{H}_{37}$ & 1.80 & $\mathrm{R}-\mathrm{CH}_{2}-\mathrm{R}$ & $\mathrm{C}_{7}$ & 125.34 & $=\mathrm{C}-\mathrm{S}$ \\
\hline
\end{tabular}




\begin{tabular}{cccccc}
\hline $\mathrm{H}_{33}$ & 1.87 & $\mathrm{R}-\mathrm{CH}-\mathrm{R}$ & $\mathrm{C}_{6}$ & 124.54 & $=\mathrm{C}-\mathrm{S}$ \\
$\mathrm{H}_{41}$ & 2.69 & $\mathrm{~N}-\mathrm{C}-\mathrm{C}-\mathrm{C}-\mathrm{H}$ & $\mathrm{C}_{2}$ & 114.24 & $\mathrm{~S}-\mathrm{C}=\mathrm{C}$ \\
$\mathrm{H}_{45}$ & 3.89 & $\mathrm{~N}-\mathrm{C}-\mathrm{H}$ & $\mathrm{C}_{3}$ & 113.76 & $\mathrm{C}=\mathrm{C}$ \\
$\mathrm{H}_{44}$ & 4.02 & $\mathrm{~N}-\mathrm{C}-\mathrm{H}$ & $\mathrm{C}_{9}$ & 103.55 & $\mathrm{O}-\mathrm{C}=\mathrm{C}$ \\
$\mathrm{H}_{50,47}$ & 6.99 & $\mathrm{C}=\mathrm{C}-\mathrm{H}$ aromatic & $\mathrm{C}_{13}$ & 102.85 & $\mathrm{O}-\mathrm{C}=\mathrm{C}$ \\
$\mathrm{H}_{48}$ & 7.81 & $\mathrm{C}=\mathrm{C}-\mathrm{H}$ aromatic & $\mathrm{C}_{10,14}$ & 100.58 & $\mathrm{O}-\mathrm{C}=\mathrm{C}$ \\
$\mathrm{H}_{51}$ & 7.88 & $\mathrm{C}=\mathrm{C}-\mathrm{H}$ aromatic & $\mathrm{C}_{17}$ & 39.05 & $\mathrm{R}{ }_{3} \mathrm{CH}$ \\
$\mathrm{H}_{49,46}$ & 8.69 & $\mathrm{C}=\mathrm{C}-\mathrm{H}$ aromatic & $\mathrm{C}_{16}$ & 38.81 & $\mathrm{~N}^{-\mathrm{CH}_{2} \mathrm{R}}$ \\
& & & $\mathrm{C}_{20}$ & 28.33 & $\mathrm{R}_{2} \mathrm{CH}_{2}$ \\
& & & $\mathrm{C}_{21}$ & 24.28 & $\mathrm{R}_{2} \mathrm{CH}_{2}$ \\
& & & $\mathrm{C}_{18}$ & 20.89 & $\mathrm{R}_{2} \mathrm{CH}_{2}$ \\
& & $\mathrm{C}_{22}$ & 17.71 & $\mathrm{R}_{2} \mathrm{CH}_{2}$ \\
& & & $\mathrm{C}_{19}$ & 8.10 & $\mathrm{RCH}_{3}$ \\
& & $\mathrm{C}_{23}$ & 4.23 & $\mathrm{RCH}_{3}$ \\
\hline
\end{tabular}

${ }^{1}$ H-NMR; The protons $\mathrm{H}_{29}$ to $\mathrm{H}_{33}$ exhibited the expected chemical shift within the range 0-2ppm, which varies depending on whether each proton is a methyl, methylene or methine in nature, and also the spatial stereo-chemical orientation which may project the proton towards or away from an electronegative group. These factors determine the de-shielding values of different atoms considering their proximity to heteroatoms. Protons from $\mathrm{H}_{41}-\mathrm{H}_{45}$ showed chemical shifts within the range $2.5 \mathrm{ppm}$ to $4.5 \mathrm{ppm}$ due to the de-shielding effect of the electronegative Nitrogen. $\mathrm{H}_{44}$ being above the plane and closest to the heteroatom is more de-shielded as evident in its chemical shift of $4.02 \mathrm{ppm}$, while $\mathrm{H}_{45}$ with a chemical shift lower as it is below the plane and hence relatively protected from the de-shielding effect of the electronegative heteroatom Nitrogen. $\mathrm{H}_{47}$ to $\mathrm{H}_{51}$ are all vinylic/aromatic protons of the furan ring, this is evident in their chemical shift values (ranging from $6.5 \mathrm{ppm}$ to $8.9 \mathrm{ppm}$ ). They experience further deshielded properties when they are localized around the highly electronegative oxygen atoms [50].

${ }^{13} \mathrm{C}$ NMR; The carbon atoms $\mathrm{C}_{2}, \mathrm{C}_{3}, \mathrm{C}_{6}$ and $\mathrm{C}_{7}$, as expected for a conjugated $\pi$ acceptor system were observed downfield with chemical shift within the range of 100-130 ppm. $\mathrm{C}_{6}$ and $\mathrm{C}_{7}$ in a single bond each with the sulphur atom were also observed downfield at $124.54 \mathrm{ppm}$ and $125.34 \mathrm{ppm}$, respectively. Carbonyl carbons $\left(\mathrm{C}_{1}\right.$ and $\left.\mathrm{C}_{4}\right)$ of the pyrroledione acceptor system were observed to suffer further deshielding effect from the doubly bonded oxygen atom, hence exhibited chemical shifts at $150.68 \mathrm{ppm}$ and 151.07 ppm, respectively. An extra shift downfield is experience for $\mathrm{C}_{8}$ and $\mathrm{C}_{12}$ because both sp ${ }^{2}$ carbon atoms are directly bonded to a highly electronegative oxygen atom, hence their peaks occurred at 136.48 ppm and $136.18 \mathrm{ppm}$, respectively. Meanwhile, $\mathrm{C}_{16}$ to $\mathrm{C}_{23}$ of the side chain attached to the nitrogen atom of the acceptor system as expected, were found to appear below $40 \mathrm{ppm}$ [50].

\subsubsection{Bond Length, Bond Angle, and Dihedral Angles}


The bond lengths and angles of all interatomic bonds and the dihedral angles in FTPF were calculated using the VEDA software. Results from the geometrical property analysis are reported in Tables S1, S2 and S3., of the supporting information. From bond length results, $\mathrm{C}=\mathrm{C}$ bonds round the A unit fall within the range 1.4192-1.4762 $\AA$, while those around the D unit ring skeleton are around 1.3660-1.4347 A. Saturated C-C bonds along the alkyl backbone have bond lengths approximately 1.5400 $\AA$, which is longer than the $\mathrm{C}=\mathrm{C}$ bonds. This same difference is seen between $\mathrm{C}=\mathrm{O}$ (approx. $1.2210 \AA$ ) and C-O (approx. 1.3620). Bond length decreases with increasing unsaturation, and unsaturated bonds are stronger than the saturated counterparts [55,56]. C-S bonds (approx. $1.7655 \AA$ ) are way longer than C-O in FTPF, this is due to the large size sulphur atom in comparison with its group counterpart oxygen [56,57]. C-H bond lengths of the ethylhexyl group lie about the natural values (approx. $1.09 \AA$ ), this is a bit longer than the unsaturated C-H (approx. 1.08 ̊). All C-N bonds in FTPF have lengths approximately equal to $1.4500 \AA$.

The bond angles for the linked carbon atoms in the azolide group of the A unit, from the results reported in on Table S2., of the supporting information, have an approximate value of $108.3^{\circ}$ (i.e. $\mathrm{C}_{1}-\mathrm{C}_{2}$ $\mathrm{C}_{3}$ and $\left.\mathrm{C}_{2}-\mathrm{C}_{3}-\mathrm{C}_{4}\right)$. Also, the angle suspended by the azolide ring on nitrogen $\left(\mathrm{C}_{1}-\mathrm{N}_{5}-\mathrm{C}_{4}\right)$ is $112.38^{\circ}$, while an angle of $124.74^{\circ}\left(\mathrm{N}_{5}-\mathrm{C}_{1}-\mathrm{O}_{27}\right)$ and $124.63^{\circ}\left(\mathrm{N}_{5}-\mathrm{C}_{4}-\mathrm{O}_{26}\right)$ suspended on the carbonyl carbon atoms of the pyrrole-dione acceptor. A notably small bong angle of $92.9^{\circ}$ is suspended on Sulphur by the two adjacent carbon atoms, this is due to repulsion offered by the valence loan pairs of electron around Sulphur, which tends to shrink the bonds together [58]. Some specific bond angle results for the furanyl D units are listed; $\mathrm{C}_{6}-\mathrm{C}_{8}-\mathrm{O}_{24}\left(116.89^{\circ}\right), \mathrm{C}_{8}-\mathrm{O}_{24}-\mathrm{C}_{11}\left(107.12^{\circ}\right), \mathrm{O}_{25}-\mathrm{C}_{15}-\mathrm{C}_{14}\left(110.44^{\circ}\right), \mathrm{C}_{7}-\mathrm{C}_{12}-\mathrm{O}_{25}\left(116.95^{\circ}\right)$, etc.

The dihedral angles, which shows the angle between two intersecting planes is the clockwise angle suspended between two sets of three connected atoms [59]. The calculated dihedral angles of FTPF calculated at CAM-B3LYP/6-31+G(d,p) levels are reported in Table S3., of the supporting information.

\subsection{Frontier Molecular Orbital (FMO) Analysis}

FMO analysis is an important approach to the study of potential materials for electronic applications, it does not only expose the energies of molecular orbitals, but also explain the distributions of these orbitals around the molecular system [22, 23]. For an appreciable knowledge on the electronic excitation properties of FTPF, the HOMO-2, HOMO-1, HOMO, LUMO, LUMO+1 and LUMO+2 diagrams were generated at CAM-B3LYP/6-31+G(d,p) levels to give pictorial explanation of the energy band gap (Eg). The electron transition properties are more informative and explicit when more molecular orbitals are considered [22, 23]. The FMO maps are visualized in Fig. 3 alongside the energies of the studied orbitals. HOMO is distributed mainly around the carbon and oxygen atoms of the donor and acceptor units of FTPF monomer, but no significant contribution was recorded from $\mathrm{N}$ and $\mathrm{S}$ atoms. From the lowest unoccupied molecular orbital (LUMO) isosurface, one can infer that LUMO spreads all over 
the donor and acceptor backbone including the $\mathrm{S}$ atom in the acceptor unit, but $\mathrm{N}$. Visuals from the plots of LUMO+1, LUMO+2 and HOMO-1 show that they are also distributed around the donor and acceptor groups, but HOMO-2 is virtually distributed all over the FTPF monomer.

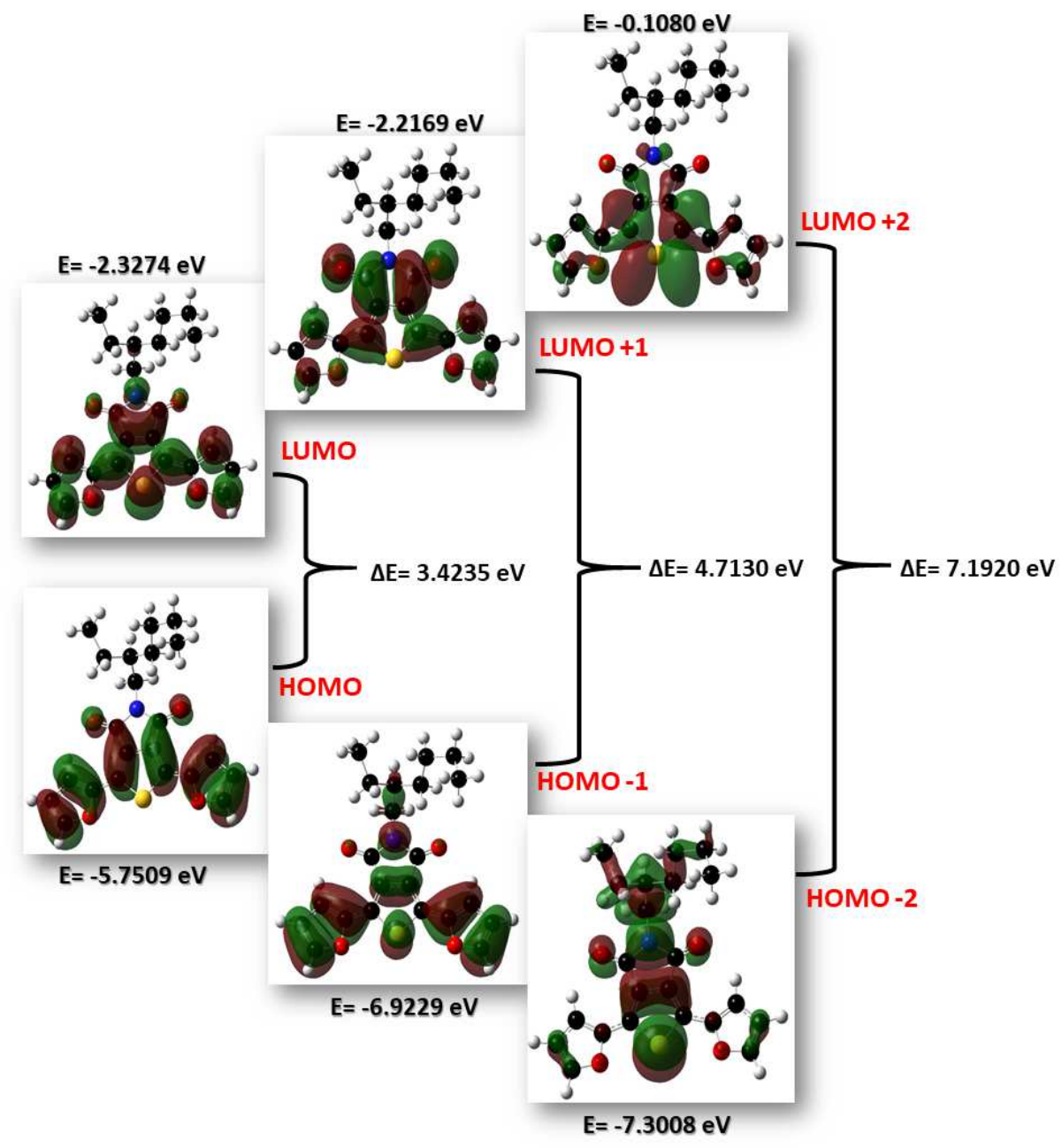

Fig. 3. HOMO-2, HOMO-1, HOMO, LUMO, LUMO+1 and LUMO+2 maps for FTPF Monomer generated with CAM-B3LYP method at $6-31+\mathrm{G}(\mathrm{d}, \mathrm{p})$ basis set.

Negative energy terms was obtained for both HOMO and LUMO (-5.7509 eV and -2.3274 eV, respectively) using DFT method at CAM-B3LYP/6-31+G(d,p) levels employed; an indication that all calculation converged appropriately at this level [21,52,60-62]. The calculated HOMO-LUMO energy gap is $3.4256 \mathrm{eV}$, a relatively small energy gap which shows that FTPF polymer is a good candidate for application as opto-electrical component [22,23] in organic electronic devices like OPV cells. In extension, HOMO-1/LUMO+1 energy gap $(4.7130 \mathrm{eV})$ calculated is also adequate when considering other possible transition energies if the molecule is incident with photons of appropriate energies. The computed HOMO and LUMO energies, and Eg of FTPF in gas, hexane, DMF and THF phases are reported in Table 3., to afford a comparative discussion. Significant increase in Eg is noticed as we introduced organic solvents, which implies that hexane, DMF and THF impedes excitation, and hence the optoelectronic properties depreciate in these solvents. The first transition in FTPF occurs with more ease than subsequent excitations in gas phase, as can be deduced from the difference in Eg at ground state 
$(3.42 \mathrm{eV})$ and excited state $(5.73 \mathrm{eV})$. Eg difference between ground and excited state are not significant in the organic solvated systems.

Table. 3. Frontier Energy Parameters for Ground and Excited states of FTPF calculated with CAMB3LYP method at 6-31+G(d,p) basis set.

\begin{tabular}{ccccccccc}
\hline $\begin{array}{c}\text { Energy } \\
\text { Parameter }\end{array}$ & \multicolumn{2}{c}{ Gas } & \multicolumn{2}{c}{ Hexane } & \multicolumn{2}{c}{ DMF } & \multicolumn{2}{c}{ THF } \\
\hline & Ground & Excited & Ground & Excited & Ground & Excited & Ground & Excited \\
HOMO $(\mathrm{eV})$ & -5.75 & -6.99 & -6.93 & -6.92 & -6.90 & -6.88 & -7.02 & -6.88 \\
LUMO $(\mathrm{eV})$ & -2.33 & -1.26 & -1.20 & -1.20 & -1.19 & -1.18 & -1.30 & -1.18 \\
Eg $(\mathrm{eV})$ & 3.42 & 5.73 & 5.73 & 5.72 & 5.71 & 5.70 & 5.72 & 5.70 \\
\hline
\end{tabular}

\subsection{Density of State (DOS) Analysis}

The Partial DOS, Total DOS and Overlap Partial DOS plots of the DAD system in gas, hexane, DMF and THF are presented in Fig. 4 to afford a comparative study of its behaviour in various solvents. For TDOS, FTPF was split into fragments; the two furanyl donors, pyrroledione acceptor and the ethylhexyl moiety. The contributions of atoms of the furanyl donor compound to TDOS is represented with red curve, pyrroledione acceptor with blue, and the ethylhexyl group with pink curve. The position of HOMO of the molecule under study is represented by the vertical dashed line on the graph, while the polarity of OPDOS of FTPF D-A-D system at any position on the graph indicates its bonding behaviour at that position [63].
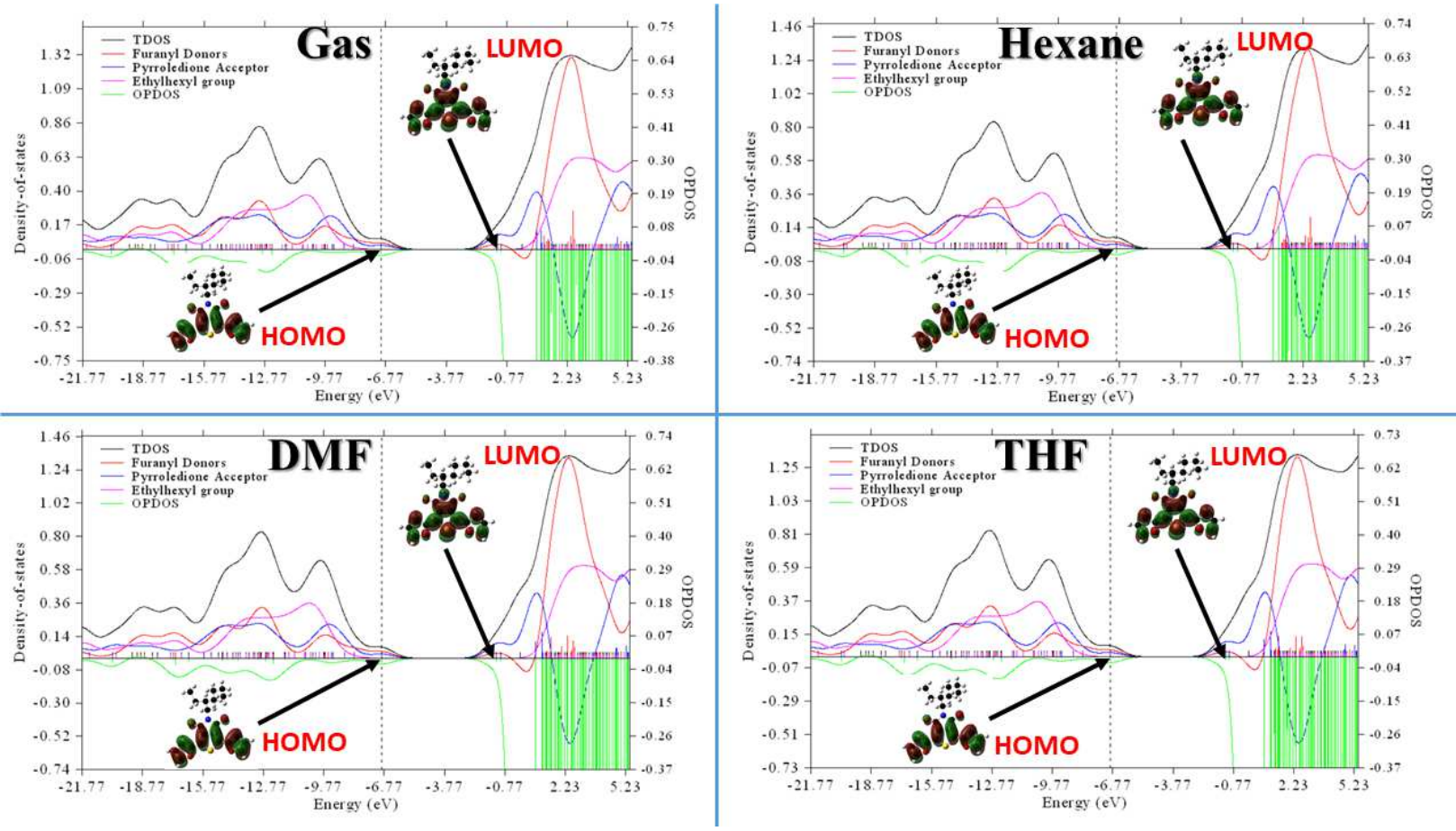
Fig. 4. DOS, TDOS and OPDOS plots for FTPF Monomer in Gas, Hexane, DMF and THF generated with CAM-B3LYP method at 6-31+G(d,p) basis set.

As can be visualized, the graph showed that the OPDOS of FTPF in DMF, gas, hexane and THF exhibited negative values at their respective HOMO positions. A negative OPDOS values represents an anti-bonding character for the molecular orbitals (MOs), but a positive OPDOS value indicates bonding character. Thus, they all show anti-bonding character at the HOMO. The furanyl donor showed maximum effect at energy position of $2.23 \mathrm{eV}$ in all solvents indicating that the donor has its highest MO contribution at this position, also an appreciable contribution from ethylhexyl group occurred at energy range of 2.23 - $4.90 \mathrm{eV}$. DOS plots of FTPF monomer in gas and all solvents considered are equivalent, which is an indication that DOS, TDOS and OPDOS of our studied monomer are independent of solvent.

\subsection{Scanning Tunneling Microscopy (STM)}

To further study this FTPF system, we conducted simulations for the scanning tunneling microscopy (STM) which helps study the structural pattern in a chemical system. STM is directly proportional to electronic distribution in a system and its maps give full information about the flow of tunneling current $(I)$ around atoms in a molecule $[63,64]$. STM plots for FTPF was done in gas, hexane, DMF and THF, in order to investigate the effect of solvent on the tunneling current around the D-A-D molecule. 

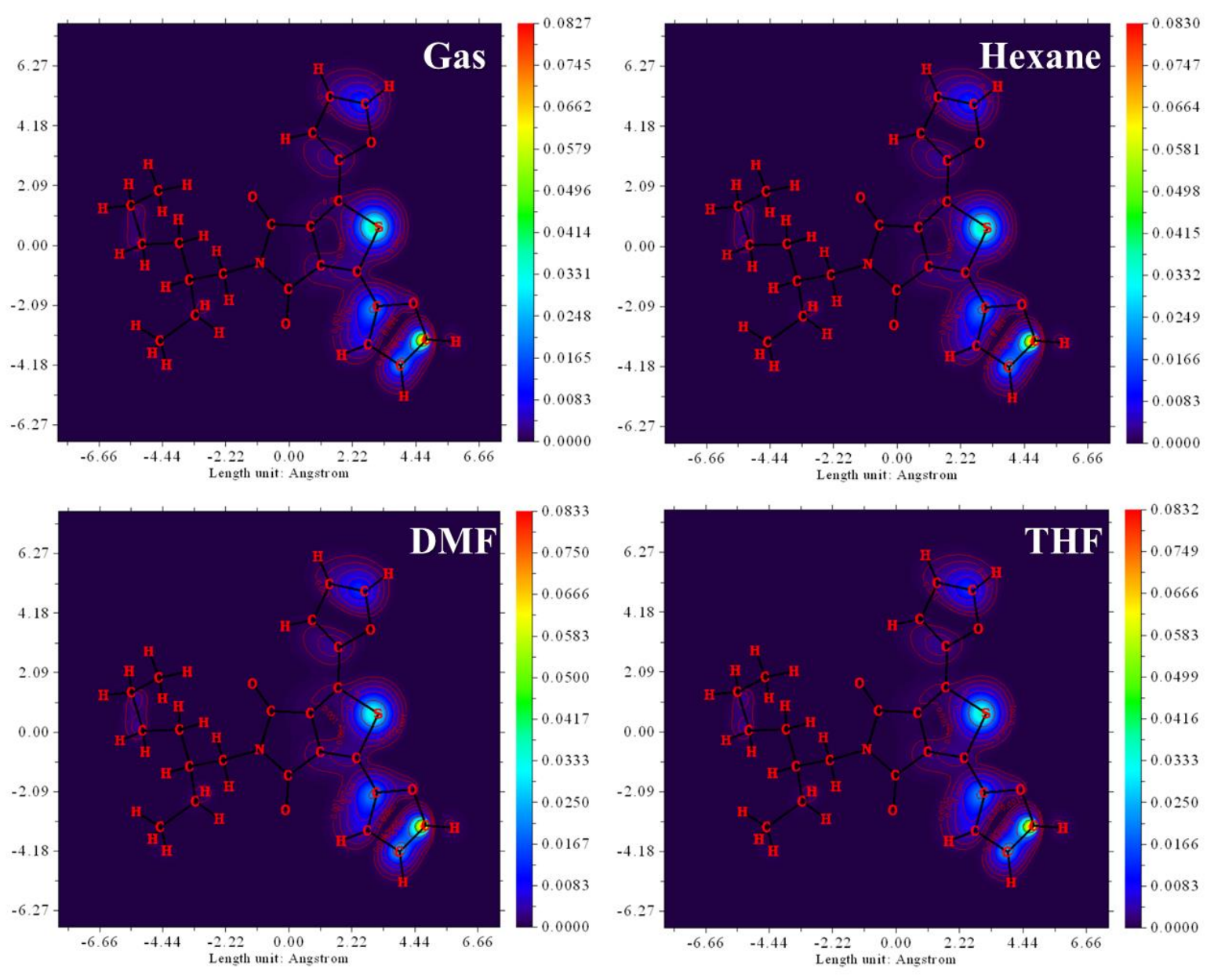

Fig. 5. STM maps for FTPF Monomer in Gas, Hexane, DMF and THF generated with CAMB3LYP method at 6-31+G(d,p) basis set.

The tunneling current is equivalent to local density of state (LDOS). An indication of a high LDOS within a region, in a molecule, is interpreted as a strong tunneling current within that region. As can be visualised in Fig. 5., the pyrroledione acceptor and the furanyl donor showed strong tunnelling current around their $\mathrm{C}$ backbone and $\mathrm{S}$ atom for all solvents, observable from the bright blue colouration with contour lines around these regions. The oxygen $(\mathrm{O})$ heteroatom of the furanyl donor is also observed to be of significant electron density and LDOS which indicates an appreciable tunneling current (I). Mild colouration on both $\mathrm{C}-\mathrm{H}$ bonds of the furanyl donors indicates the electronic distribution around these regions. It is worthy to note that change in solvents had no effect on the STM map of FTPF, as can be seen from the maps for gas, hexane, DMF and THF, in Fig. 5. 


\subsection{Molecular Electrostatic Potential (MEP) Analysis}

The electrostatic potential plot comprises a mixture of colours that ranges from blue, red to green. The zones with negative potentials, i.e. high electron densities are transcribed as red with negative values for isosurfaces; while the electron deficient zones are blueish (positive isosurface values are recorded for such surfaces) $[63,65]$. From the plotted MEP map showing four planar view directions of FTPF in gas visualized in Fig. 6., it is visible that the high electron densities are concentrated around the very electronegative atoms in both $\mathrm{D}$ and $\mathrm{A}$ fragment of the monomer; D (oxygen) and A (oxygen, nitrogen and sulphur) and also around the conjugated carbon backbone, which implies that high electron densities are distributed along these paths. The isosurface values of the electronegative atoms in the compound decreases in this order: $\mathrm{O}>\mathrm{S}>\mathrm{N}$. This implies that the electronic dependent activities of FTPF are expected along the D-A-D linked fragments, such properties like electron and hole excitations, energy gap reduction, and other optical properties will optimize as monomers polymerizes to form elongated conjugated backbone $[66,67]$.

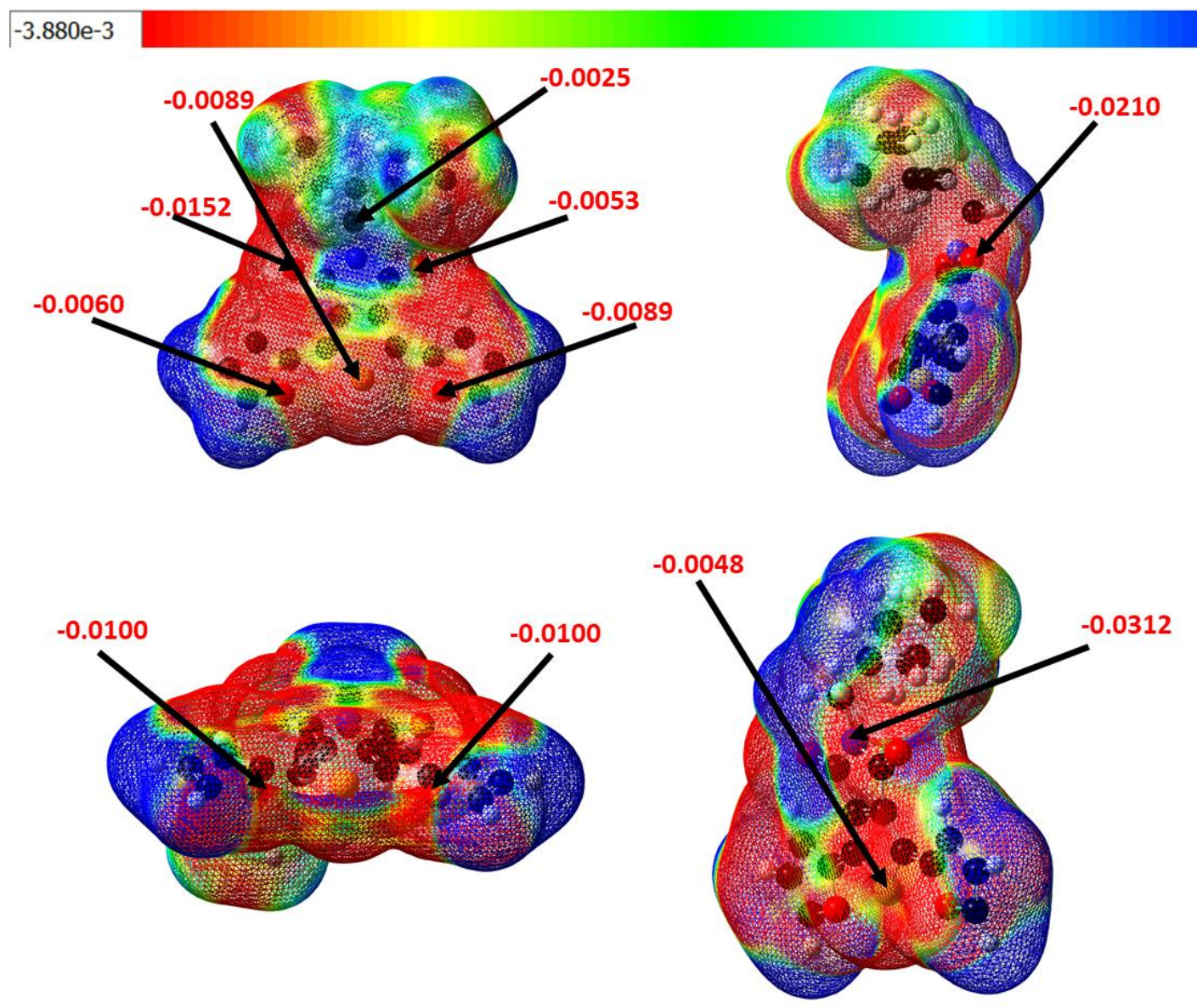

Fig. 6. MEP maps for FTPF Monomer in Gas (four viewing directions), generated with CAMB3LYP method at 6-31+G(d,p) basis set. 
In the simulated ESP map, the yellowish-red region shows the transition from a low electron density region to a high electron density region (red) [63]. Such distributions are visible around the non-polar ethylhexyl group on the A unit. Reactivity, polar properties, electronic transitions and its accompanied properties are not expected around these regions $[63,65]$.

\subsection{Atomic Dipole Corrected Hirshfield (ADCH) Atomic Charge Properties}

We further studied the distribution of charges around FTPF monomer by conducting ADCH population analysis, so as to provide appropriate and corrected Hirshfield charge distribution than the one initially employed by Tanaka \& Chujo [68]. ADCH approach is a more improved method in the determination of the activity sites within a molecule as a dependent property of electron density distribution obtainable from DFT studies [52]. The ADCH and Hirshfield results for all atomic elements in FTPF monomer in gas, hexane, DMF and THF solvent systems, calculated with CAM-B3LYP method at $6-31+\mathrm{G}(\mathrm{d}, \mathrm{p})$ basis level are presented on Table 4.

Table 4. Results from ADCH Atomic Charge Analysis for FTPF Monomer in Gas, Hexane, DMF and THF calculated with CAM-B3LYP method at 6-31+G(d,p) basis set.

\begin{tabular}{|c|c|c|c|c|c|c|c|c|}
\hline & \multicolumn{2}{|c|}{ Gas } & \multicolumn{2}{|c|}{ Hexane } & \multicolumn{2}{|c|}{ DMF } & \multicolumn{2}{|c|}{ THF } \\
\hline Atoms & $\mathrm{ADCH}$ & Hirshfield & $\mathrm{ADCH}$ & Hirshfield & $\mathrm{ADCH}$ & Hirshfield & $\mathrm{ADCH}$ & Hirshfield \\
\hline $\mathrm{C}_{1}$ & 0.4488 & 0.1860 & 0.4586 & 0.1873 & 0.4667 & 0.1907 & 0.4660 & 0.1896 \\
\hline $\mathrm{C}_{2}$ & -0.1281 & -0.0462 & -0.1275 & -0.0456 & -0.1235 & -0.0430 & -0.1251 & -0.0440 \\
\hline $\mathrm{C}_{3}$ & -0.0808 & -0.0462 & -0.0752 & -0.0456 & -0.0575 & -0.0429 & -0.0633 & -0.0438 \\
\hline $\mathrm{C}_{4}$ & 0.2614 & 0.1853 & 0.2654 & 0.1868 & 0.2789 & 0.1908 & 0.2709 & 0.0189 \\
\hline $\mathrm{N}_{5}$ & -0.0040 & -0.0341 & -0.0005 & -0.0327 & 0.0053 & -0.0291 & 0.0035 & -0.0302 \\
\hline $\mathrm{C}_{6}$ & 0.0101 & -0.0004 & 0.0086 & -0.0006 & 0.0038 & -0.0018 & 0.0053 & -0.0014 \\
\hline $\mathrm{C}_{7}$ & 0.0028 & -0.0005 & 0.0005 & -0.0007 & -0.0036 & -0.0017 & -0.0030 & -00014 \\
\hline $\mathrm{C}_{8}$ & 0.0537 & 0.0491 & 0.0543 & 0.0468 & 0.0565 & 0.0423 & 0.0560 & 0.0436 \\
\hline $\mathrm{C}_{9}$ & -0.1108 & -0.5486 & -0.1153 & -0.0568 & -0.1271 & -0.0618 & -0.1235 & -0.0602 \\
\hline $\mathrm{C}_{10}$ & -0.1548 & -0.0699 & -0.1569 & 0.0705 & -0.1619 & -0.0725 & -0.1604 & -0.0719 \\
\hline $\mathrm{C}_{11}$ & -0.0452 & 0.0309 & -0.0455 & 0.0321 & -0.0458 & 0.0344 & -0.0458 & 0.0338 \\
\hline $\mathrm{C}_{12}$ & 0.0602 & 0.0490 & 0.0646 & 0.0468 & 0.0763 & 0.0424 & 0.0736 & 0.0436 \\
\hline $\mathrm{C}_{13}$ & -0.1121 & -0.0550 & -0.1174 & -0.0568 & -0.1325 & -0.0619 & -0.1280 & -0.0603 \\
\hline $\mathrm{C}_{14}$ & -0.1552 & -0.0699 & -0.1578 & -0.0706 & -0.1644 & -0.0725 & -0.1625 & -0.0719 \\
\hline $\mathrm{C}_{15}$ & -0.0455 & 0.0309 & -0.0467 & 0.0320 & -0.0491 & 0.0343 & -0.0485 & 0.0337 \\
\hline $\mathrm{C}_{16}$ & -0.1122 & 0.0042 & -0.1125 & 0.0049 & -0.1117 & 0.0066 & -0.1121 & 0.0061 \\
\hline $\mathrm{C}_{17}$ & -0.0650 & -0.0125 & -0.0641 & -0.0119 & -0.0607 & -0.0101 & -0.0620 & -0.0107 \\
\hline $\mathrm{C}_{18}$ & -0.1480 & -0.0541 & -0.1471 & -0.0541 & -0.1454 & -0.0543 & -0.1460 & -0.0906 \\
\hline $\mathrm{C}_{19}$ & -0.2411 & -0.0882 & -0.2426 & -0.0892 & -0.2455 & -0.0911 & -0.2447 & -0.0552 \\
\hline $\mathrm{C}_{20}$ & -0.1543 & -0.0552 & -0.1540 & -0.0552 & -0.1538 & -0.0553 & -0.1538 & -0.0488 \\
\hline $\mathrm{C}_{21}$ & -0.1379 & -0.0480 & -0.1378 & -0.0481 & -0.1381 & -0.0482 & -0.1379 & -0.0474 \\
\hline $\mathrm{C}_{22}$ & -0.1439 & -0.0461 & -0.1444 & -0.0466 & -0.1460 & -0.0478 & -0.1455 & -0.0916 \\
\hline $\mathrm{C}_{23}$ & -0.2532 & -0.0887 & -0.2549 & -0.0899 & -0.2582 & -0.0922 & -0.2573 & -0.0941 \\
\hline $\mathrm{O}_{24}$ & -0.1274 & -0.0896 & -0.1298 & -0.0915 & -0.1329 & -0.0949 & -0.1322 & -0.0941 \\
\hline $\mathrm{O}_{25}$ & -0.1268 & -0.0896 & -0.1293 & -0.0916 & -0.1321 & -0.0950 & -0.1316 & -0.0940 \\
\hline $\mathrm{O}_{26}$ & -0.3470 & -0.2557 & $-\mathbf{0 . 3 5 7 7}$ & -0.2608 & -0.3749 & -0.2692 & -0.3704 & -0.2669 \\
\hline
\end{tabular}




\begin{tabular}{lcccccccc}
\hline $\mathrm{O}_{27}$ & $\mathbf{- 0 . 4 4 2 5}$ & -0.2536 & $\mathbf{- 0 . 4 5 5 9}$ & -0.2587 & $\mathbf{- 0 . 4 7 2 0}$ & -0.2673 & $\mathbf{- 0 . 4 6 8 7}$ & -0.2650 \\
$\mathrm{~S}_{28}$ & $\mathbf{0 . 0 8 5 5}$ & 0.1087 & $\mathbf{0 . 0 7 4 5}$ & 0.1036 & $\mathbf{0 . 0 4 9 1}$ & 0.0932 & $\mathbf{0 . 0 5 6 6}$ & 0.0962 \\
$\mathrm{H}_{29}$ & 0.0823 & 0.0289 & 0.0823 & 0.0289 & 0.0803 & 0.0280 & 0.0812 & 0.0283 \\
$\mathrm{H}_{30}$ & 0.0877 & 0.0295 & 0.0876 & 0.0229 & 0.0869 & 0.0297 & 0.0872 & 0.0297 \\
$\mathrm{H}_{31}$ & 0.0781 & 0.0268 & 0.0788 & 0.0271 & 0.0818 & 0.0283 & 0.0806 & 0.0279 \\
$\mathrm{H}_{32}$ & 0.0771 & 0.0262 & 0.0770 & 0.0263 & 0.0756 & 0.0257 & 0.0763 & 0.0267 \\
$\mathrm{H}_{33}$ & 0.0777 & 0.0262 & 0.0782 & 0.0264 & 0.0799 & 0.0272 & 0.0793 & 0.0268 \\
$\mathrm{H}_{34}$ & 0.0743 & 0.0253 & 0.0756 & 0.0260 & 0.0786 & 0.0278 & 0.0776 & 0.0273 \\
$\mathrm{H}_{35}$ & 0.0758 & 0.0252 & 0.0768 & 0.0258 & 0.0789 & 0.0271 & 0.0782 & 0.0268 \\
$\mathrm{H}_{36}$ & 0.0589 & 0.0195 & 0.0589 & 0.0198 & 0.0592 & 0.0206 & 0.0591 & 0.0203 \\
$\mathrm{H}_{37}$ & 0.0701 & 0.0243 & 0.0681 & 0.0239 & 0.0632 & 0.0210 & 0.0648 & 0.0218 \\
$\mathrm{H}_{38}$ & 0.0914 & 0.0303 & 0.0909 & 0.0303 & 0.0879 & 0.0295 & 0.0891 & 0.0299 \\
$\mathrm{H}_{39}$ & 0.0743 & 0.0259 & 0.0754 & 0.0264 & 0.0787 & 0.2781 & 0.0776 & 0.0277 \\
$\mathrm{H}_{40}$ & 0.0799 & 0.0266 & 0.0805 & 0.0271 & 0.0820 & 0.0281 & 0.0816 & 0.0277 \\
$\mathrm{H}_{41}$ & 0.0675 & 0.0210 & 0.0643 & 0.0192 & 0.0572 & 0.0154 & 0.0593 & 0.0165 \\
$\mathrm{H}_{42}$ & 0.0714 & 0.0241 & 0.0720 & 0.0246 & 0.0727 & 0.0254 & 0.0726 & 0.0252 \\
$\mathrm{H}_{43}$ & 0.0808 & 0.0293 & 0.0839 & 0.0312 & 0.0904 & 0.0352 & 0.0885 & 0.0340 \\
$\mathrm{H}_{44}$ & 0.0978 & 0.0395 & 0.0998 & 0.0407 & 0.1036 & 0.0429 & 0.1025 & 0.0423 \\
$\mathrm{H}_{45}$ & 0.0949 & 0.0386 & 0.0967 & 0.0397 & 0.1004 & 0.0417 & 0.0993 & 0.0411 \\
$\mathrm{H}_{46}$ & 0.1235 & 0.0503 & 0.1220 & 0.0496 & 0.1194 & 0.0484 & 0.1201 & 0.0487 \\
$\mathrm{H}_{47}$ & 0.1545 & 0.0575 & 0.1611 & 0.0618 & 0.1728 & 0.0692 & 0.1696 & 0.0673 \\
$\mathrm{H}_{48}$ & 0.1551 & 0.0659 & 0.1634 & 0.0713 & 0.1783 & 0.0811 & 0.1743 & 0.0784 \\
$\mathrm{H}_{49}$ & 0.1311 & 0.0504 & 0.1299 & 0.0496 & 0.1278 & 0.0484 & 0.1284 & 0.0487 \\
$\mathrm{H}_{50}$ & 0.1545 & 0.0576 & 0.1611 & 0.0618 & 0.1728 & 0.0692 & 0.1696 & 0.0672 \\
$\mathrm{H}_{51}$ & 0.1552 & 0.0660 & 0.1634 & 0.0713 & 0.1784 & 0.0812 & 0.1743 & 0.0785 \\
\hline & & & & & & & & \\
\hline
\end{tabular}

Atoms with high negative ADCH charges are highly susceptible to electrophilic substitution. The carbonyl oxygen atoms on the pyrroledione acceptor showed highest tendencies as electrophilic substitution sites of reaction, this is inferred from the high negative $\mathrm{ADCH}$ values; $\mathrm{O}_{26}(-0.3470)$ and $\mathrm{O}_{27}$ $(-0.4425)$ in gas, $\mathrm{O}_{26}(-0.3577)$ and $\mathrm{O}_{27}(-0.4559)$ in hexane, $\mathrm{O}_{26}(-0.3749)$ and $\mathrm{O}_{27}(-0.4720)$ in DMF and $\mathrm{O}_{26}(-0.3704)$ and $\mathrm{O}_{27}(-0.4687)$ in THF. Also, the carbon of the terminal methyl groups of ethylhexyl moiety of FTPF are observed to be the good sites for electrophilic substitution, owing to their relatively high negative $\mathrm{ADCH}$ outputs; $\mathrm{C}_{19}(-0.2411)$ and $\mathrm{C}_{23}$ (-0.2532) in gas, $\mathrm{C}_{19}(-0.2426)$ and $\mathrm{C}_{23}(-0.2549)$ in hexane, $\mathrm{C}_{19}(-0.2455)$ and $\mathrm{C}_{23}(-0.2582)$ in $\mathrm{DMF}$ and $\mathrm{C}_{19}(-0.2447)$ and $\mathrm{C}_{23}(-0.2573)$ in THF. The pyrroledione acceptor Sulphur atom exhibited positive ADCH (0.0855) in gas, showing that it is a nucleophilic reaction site.

Considering the effect of solvent on the ADCH charge distribution, from results in Table 4, one can see that no significant change was observed for change in solvent from gas, hexane, DMF to THF, and all inferences obey the electrophilic and nucleophilic activities on the various atoms of FTPF monomer. It is important to note that DMF gave the highest shift from results obtained in no solvent (gas). Also, it is visible that the magnitude of $\mathrm{ADCH}$ values for both positive and negative charges of 
different atoms are higher than the Hirshfield charges, which are more adequate in determination and explanation of charge moment distributions [52].

\subsection{Vertical Excitation Studies using Hole-Electron Analysis}

In order to understand the types and nature of the first five excitations $\left(S_{0} \rightarrow S_{1}, S_{0} \rightarrow S_{2}, S_{0} \rightarrow S_{3}, S_{0} \rightarrow\right.$ $S_{4}$ and $S_{0} \rightarrow S_{5}$ ) [23], the hole-electron excitation properties of FTPF was studied in gas and DMF. The choice of solvent (DMF) for this analysis was influenced by the results obtained from other analysis that considered the effects of hexane, DMF and THF on the properties of our studied D-A-D molecule. DMF; an aprotic polar solvent offered the highest deviation to the properties of FTPF from its isolated form than every other solvent. Various exciton indices were calculated via a single point TD-SCF CAM-B3LYP/6$31+\mathrm{G}(\mathrm{d}, \mathrm{p})$ calculations. Various hole and electron isosurfaces were also plotted, alongside heat map distributions of fragments for direct visualization analyses [23].

\subsubsection{Hole-Electron excitations}

For this study, quantitative excitation determinant indices $\left(S_{r}, D, H, t\right.$, hole delocalization and electron delocalization) were generated using Multiwfn programme [46]. For molecular orbitals, the net configuration coefficients equal 1 . This implies that $\int \rho^{\text {hole }}(r) d r$ and $\int \rho^{\text {ele }}(r) d r$ are both equal to 1 . All hole and electron distribution should satisfy this situation [48]. Computationally, all the considered indices were determined by employing equations 1-9 [48]. One can interpret if an excitation is a localized excitation (LE), charge transfer (CT) or a Rydberg type depending on the values of various indices studied. Also, maps of hole and electron, centroids of hole and electron, $\mathrm{Sr}$ and charge density difference (CCD) shows the positions of excitation around the molecule under consideration [22,23]. Results from the hole-electron excitation studies of FTPF monomer in gas and DMF are reported in Table 5., while the plotted excitation isosurfaces are provided in Fig. 7. 


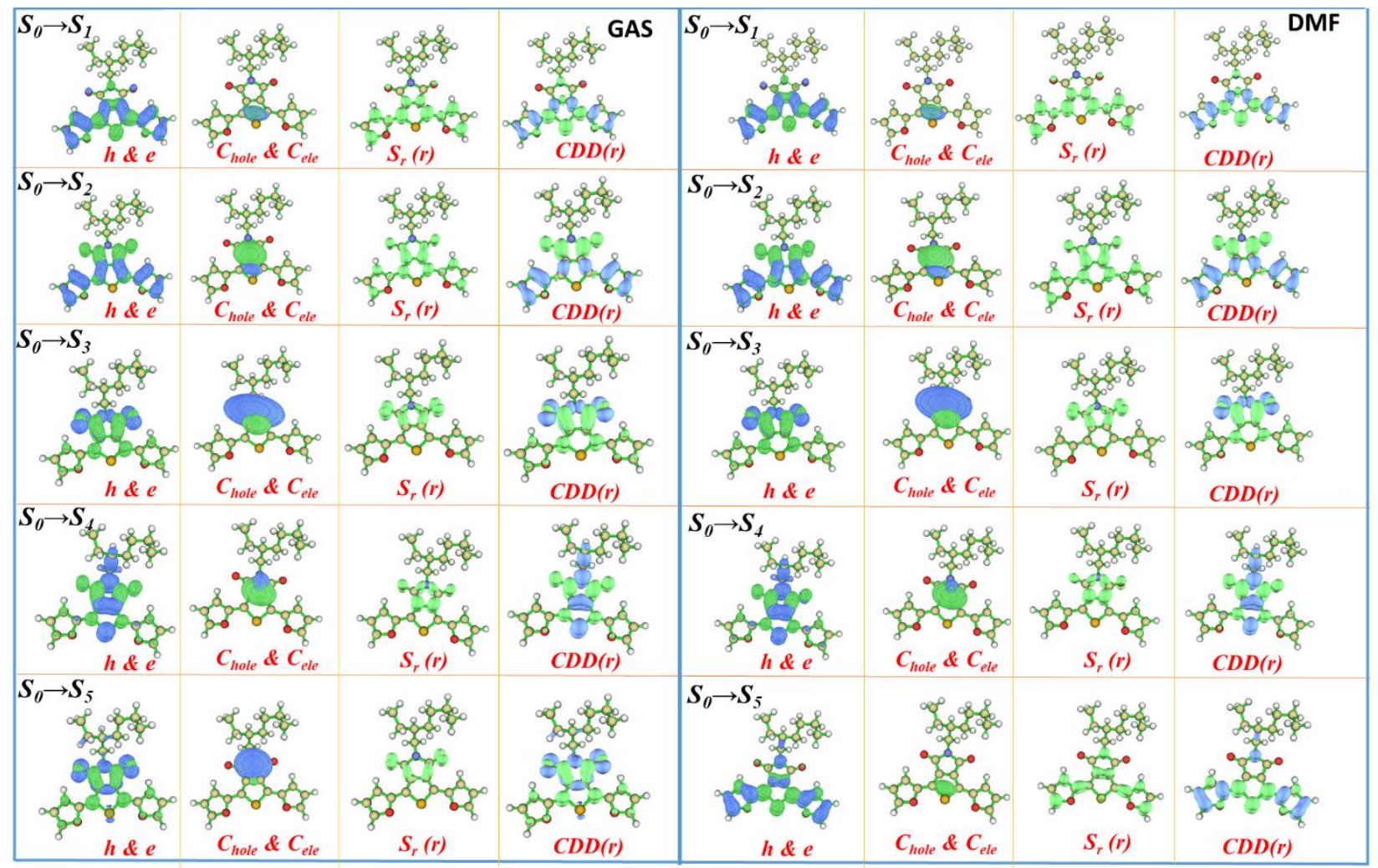

Fig. 7. Isosurface maps of Hole and Electron, Centroids of Hole and Electron, $\mathrm{Sr}$ and CDD of FTPF generated with TD-SCF CAM-B3LYP method at 6-31+G(d,p) basis set.

$\mathrm{Sr}$ is a function used to measure the overlap between hole and electron densities, it quantifies the spatial presence of hole and electron [48]. Sr is an important parameter for defining the excitation types from hole-electron interaction, in conjunction with other indices. The $D$ index defines the total magnitude of CT length, it is equal to the distance between the hole and electron centroids ( $C_{\text {hole }}$ and $\left.C_{\text {ele }}\right)$ [48]. $H$ index is an overall estimation of the average extent of spatial extension of hole and electron distribution in all coordinates. The assignment of the breath of distribution of hole and electron during an excitation process is defined by $H$ index [48]. The measure of hole and electron separation degree in charge transfer dimension is connoted in $t$ index value. For $t<0$, hole and electron separation is not large due to charge transfer, while when $t>0$, one can say there exist a substantial separation between hole and electron. The magnitude of $t$ index can be transformed to the extent of separation between hole and electron for the particular excitation. The spatial distribution of hole and electron at excited state are defined by the HDI and EDI respectively. The values of HDI and EDI is a signal for whether the excitation is highly localized (high HDI and EDI) or delocalized (low HDI and EDI) [48]. 
Table 5. Results from the Hole-Electron Excitation studies of FTPF in gas and DMF calculated with TD-SCF CAM-B3LYP method at 6-31+G(d,p) basis set.

\begin{tabular}{llllllll}
\hline & $\boldsymbol{D}(\mathbf{\AA})$ & $\boldsymbol{S} \boldsymbol{r}(\mathbf{a . u})$ & $\boldsymbol{H}(\mathbf{\AA})$ & $\boldsymbol{t}(\mathbf{\AA})$ & $\mathbf{E}_{\text {coul }}(\mathbf{e V})$ & HDI & EDI \\
\hline $\boldsymbol{S}_{\boldsymbol{0} \rightarrow \boldsymbol{S}_{\boldsymbol{1}}}$ & & & & & & & \\
$\mathrm{Gas}$ & 0.03 & 0.74 & 3.33 & -2.61 & 4.36 & 6.11 & 6.40 \\
$\mathrm{DMF}$ & 0.11 & 0.77 & 3.35 & -1.99 & 4.51 & 6.17 & 6.46 \\
$\boldsymbol{S}_{\boldsymbol{0} \rightarrow \boldsymbol{S}_{\boldsymbol{2}}}$ & & & & & & & \\
$\mathrm{Gas}$ & 1.68 & 0.68 & 3.15 & 0.10 & 4.12 & 6.00 & 8.30 \\
$\mathrm{DMF}$ & 1.76 & 0.67 & 3.16 & 0.22 & 4.05 & 6.05 & 8.30 \\
$\boldsymbol{S}_{\boldsymbol{0} \rightarrow \boldsymbol{S}_{\boldsymbol{3}}}$ & & & & & & & \\
$\mathrm{Gas}$ & 1.45 & 0.44 & 2.64 & 0.01 & 4.27 & 15.89 & 7.46 \\
$\mathrm{DMF}$ & 1.38 & 0.45 & 2.67 & -0.09 & 4.12 & 15.03 & 7.40 \\
$\boldsymbol{S}_{\boldsymbol{0} \rightarrow \boldsymbol{S}_{\boldsymbol{4}}}$ & & & & & & & \\
$\mathrm{Gas}$ & 0.47 & 0.49 & 2.86 & -1.45 & 4.33 & 8.65 & 8.08 \\
$\mathrm{DMF}$ & 0.44 & 0.50 & 2.88 & -1.47 & 4.38 & 8.38 & 8.14 \\
$\boldsymbol{S}_{\boldsymbol{0}} \rightarrow \boldsymbol{S}_{\boldsymbol{5}}$ & & & & & & & \\
$\mathrm{Gas}$ & 1.69 & 0.41 & 2.83 & 0.02 & 3.32 & 12.18 & 6.10 \\
$\mathrm{DMF}$ & 0.07 & 0.62 & 3.57 & -1.81 & 3.76 & 6.29 & 6.21 \\
\hline
\end{tabular}

3.7.1.1 First Excitation $\left(\boldsymbol{S}_{0} \rightarrow \boldsymbol{S}_{1}\right)$; $S_{0} \rightarrow S_{1}$ exhibited the least value of $D$ index $(0.03 \AA$ and $0.11 \AA$ in gas and DMF, respectively), which is tentatively indicative of a localized or Rydberg excitation. $S r$ index ( 0.74 a.u. in gas and 0.77 a.u. in DMF) of $S_{0} \rightarrow S_{l}$ is the highest in the group, an $\pi \rightarrow \pi^{*}$ excitation is perceived. A localized $\pi \rightarrow \pi^{*}$ charge transfer is inferable when $D, S r$ and $t(-2.61 \AA$ in gas and $-1.99 \AA$ in DMF) are considered. A high negative $t$ index value is indicative of low CT between hole and electron, this is supported by the HDI (6.11 and 6.17 in gas and DMF, respectively) and EDI (6.40 and 6.46 in gas and DMF, respectively) values, which are very low, showing delocalization. From Fig. 7., the hole and electron of FTPF in both gas and DMF are conspicuously located around the D-A-D moiety, with the holes occupying the fused heteroatoms (Oxygen and Sulphur), while the electron (blue lobes) are distributed along the rings. One can conclude that $S_{0} \rightarrow S_{l}$ is a delocalized $\pi \rightarrow \pi^{*}$ excitation originating from the unsaturated carbon atoms linked with fused oxygen of the furanyl donor and Sulphur of the pyrroledione acceptor along the conjugated system.

3.7.1.2 Second Excitation $\left(\boldsymbol{S}_{\boldsymbol{0}} \rightarrow \boldsymbol{S}_{2}\right)$; From $D$ index values in Table 5., Relatively high values are recorded for $S_{0} \rightarrow S_{2}(1.68 \AA$ in gas and $1.76 \AA$ in DMF), one can propose a charge transfer for such. But, these values are lower than those classified as CT by Louis et. al. [21-23], hence other indices are to be considered before assignment. $t$ index values of ( $0.10 \AA$ and $0.22 \AA$ in gas and DMF, respectively) for the second excitation $\left(S_{0} \rightarrow S_{2}\right)$ is greater than zero $(0)$, showing that the separation of hole from electron is not low, hence not a charge transfer. Also, from the $S r$ index ( 0.68 a.u. in 0.67 a.u. in gas and DMF, respectively), which is relatively high indicates that $S_{0} \rightarrow S_{2}$ is a $\pi \rightarrow \pi^{*}$ transition. $S_{0} \rightarrow S_{2}$ is confirmed to be 
a delocalized $\pi \rightarrow \pi^{*}$ transition. The relatively low HDI (6.00 and 6.05 in gas and DMF) and EDI (8.30 in both gas and DMF) values suggests a delocalized excitation system. Complementing this information with the visualized hole and electron isosurface for $S_{0} \rightarrow S_{2}$ in Fig. 7., where the blue (hole) and green (electron) lobes are spread around both donors and acceptor, this is as a result of $\pi \rightarrow \pi^{*}$ transitions along the conjugated furanyl-pyrroledione-furanyl ring backbone.

3.7.1.3 Third Excitation $\left(\boldsymbol{S}_{\boldsymbol{0}} \rightarrow \boldsymbol{S}_{3}\right)$; the third excitation exhibits a $D$ index value of $1.45 \AA$ in gas and 1.38 in DMF, this is very close to the values obtained for $S_{0} \rightarrow S_{2}$; a tentative charge transfer. FTPF exhibited a relatively low $S r$ index value ( 0.44 a.u. and 0.45 a.u. in gas and DMF) for $S_{0} \rightarrow S_{3}$, showing a possible $\mathrm{n} \rightarrow \pi^{*}$. From $t$ index values ( $0.10 \AA$ and -0.09 in gas and DMF, respectively) obtained, $S_{0} \rightarrow S_{3}$ is proposed to be a localized or Rydberg excitation in gas, but charge transfer in DMF. Here, the effect of DMF on the hole-electron overlap is significant. The local status of $S_{0} \rightarrow S_{3}$ is confirmed from the high HDI (15.89 and 15.03 in gas and DMF, respectively) value. By visualizing the hole and electron isosurfaces, it is evident that the hole and electrons are distributed around the carbonyl On the azolide portion of the acceptor. $S_{0} \rightarrow S_{3}$ originates from the lone pairs of electrons of the carbonyl oxygen atoms.

3.7.1.4 Fourth Excitation $\left(\boldsymbol{S}_{\boldsymbol{0}} \rightarrow \boldsymbol{S}_{4}\right)$; From the relatively low $D(0.47 \AA$ in gas and $0.44 \AA$ in DMF $)$ and $S r$ (0.49 a.u. in gas and 0.50 a.u. in DMF) suggest a localized $n \rightarrow \pi^{*}$ excitation for $S_{0} \rightarrow S_{4}$. Negative $t$ index values; -1.45 and -1.47 in gas and DMF, respectively supports the fat that the transition is localized (the separation between hole and electron is minimal). Also, average HDI (8.65 and 8.38 in gas and DMF) and EDI (8.08 and 8.14 in gas and DMF) validates a local excitation (LE) of $n \rightarrow \pi^{*}$ characterized to originate from heteroatoms (carbonyl oxygen) of the pyrroledione A unit. It is visible from Fig. 7., that during excitation, the hole is domiciled on the carbonyl oxygen, while electron extends locally around the A unit. $\mathrm{Sr}$ isosurfaces shows the overlap of hole and electron on the acceptor group, which confirms the localization of $S_{0} \rightarrow S_{4}$ excitation.

3.7.1.5 Fifth Excitation $\left(\boldsymbol{S}_{\boldsymbol{0}} \rightarrow \boldsymbol{S}_{5}\right)$; $D$ index of the fifth excitation is relatively high; $1.69 \AA$ in gas, but extremely reduced in DMF $(0.07 \AA)$, this is where the effect of change in solvent is highest. The $t$ index is also bipolar in gas and DMF, excitation is proposed to be local or Rydberg in gas $(t=0.02)$, but CT in DMF ( $t=-1.81$ ), another major shift. From $S r$ values, one can propose an $\mathrm{n} \rightarrow \pi^{*}$ transition for $S_{0} \rightarrow S_{5}$ in gas, and $\pi \rightarrow \pi^{*}$ in DMF. Also, observing the hole and electron isosurface on Fig. 7., where the hole and electron of $S_{0} \rightarrow S_{5}$ excitation is localized on the acceptor unit in gas, but extends all over both acceptor and two donor units in DMF. HDI and EDI values (12.18 and 6.10, respectively in gas) supports a localized system, but this pair reduced for DMF, hence a delocalized transition is proposed. 
The effect of DMF solvent is seen for $S_{0} \rightarrow S_{3}$ and $S_{0} \rightarrow S_{5}$, which a greater twist of the type of excitation transition in $S_{0} \rightarrow S_{5}$ (where an $\mathrm{n} \rightarrow \pi^{*}$ changed to $\pi \rightarrow \pi^{*}$ due to the change from gas to DMF solvent). The various studied excitations are summarized in Table 6., for easy correlation and visualization, their behaviour in the two systems are presented.

Table 6. Summary of the difference kinds and locations of Excitation of FTPF in gas and DMF from Hole-Electron Excitation studies with TD-SCF CAM-B3LYP method at 6-31+G(d,p) basis set.

\begin{tabular}{lll}
\hline Excitations & \multicolumn{1}{c}{ Excitation Type } \\
\hline$S_{0} \rightarrow S_{1}$ & $\begin{array}{l}\text { Gas } \\
\text { Delocalized } \pi \rightarrow \pi^{*} \text { Rydberg excitation } \\
\text { originating from C }=\text { C } \pi \text { bonds of D-A-D } \\
\text { system. }\end{array}$ & Same. \\
$S_{0 \rightarrow S_{2}}$ & $\begin{array}{l}\text { A } \pi \rightarrow \pi^{*} \text { LE extended over the D-A-D } \\
\text { backbone. }\end{array}$ & Same. \\
$S_{0} \rightarrow S_{3}$ & $\begin{array}{l}\text { A localized } \mathrm{n} \rightarrow \pi^{*} \text { transition around the } \\
\text { carbonyl on the azolide moiety of A unit. }\end{array}$ & $\begin{array}{l}\text { An } \mathrm{n} \rightarrow \pi^{*} \text { CT originating from the } \\
\text { lone pairs of carbonyl oxygen. }\end{array}$ \\
$S_{0 \rightarrow S_{4}}$ & $\begin{array}{l}\text { An } \mathrm{n} \rightarrow \pi^{*} \text { LE originating from the carbonyl } \\
\text { oxygen atoms of the A unit. } \\
\text { An } \mathrm{n} \rightarrow \pi^{*} \text { LE on the A unit (equivalent to } \\
\left.S_{0} \rightarrow S_{4}\right)\end{array}$ & $\begin{array}{l}\text { Same. } \\
\text { Delocalized } \pi \rightarrow \pi^{*} \text { extended over the } \\
\text { D-A-D backbone. }\end{array}$ \\
\hline
\end{tabular}

\subsubsection{Heat Maps Analysis}

In order to further expose the major character of our studied D-A-D monomer, the contributions of the different fragments to hole and electron were plotted in the form of heat maps [23]. From heat maps, we can understand the source fragment of the excited electrons and their location after excitation, this gives more meaning to the results from hole and electron indices discussed in section 3.7.3. in order to plot the heat map of 5-(2-ethylhexyl)-1,3-di (furan-2-yl)-4H-thieno [3,4-c]pyrrole-4,6(5H)-dione, the molecule was split into three (3) fragments; Frag 1 is the two furanyl donors units, frag 2 is the pyrroledione acceptor unit and frag 3 is the ethylhexyl group. The plotted heat maps for FTPF monomer in gas and DMF is presented in Fig. 8. 


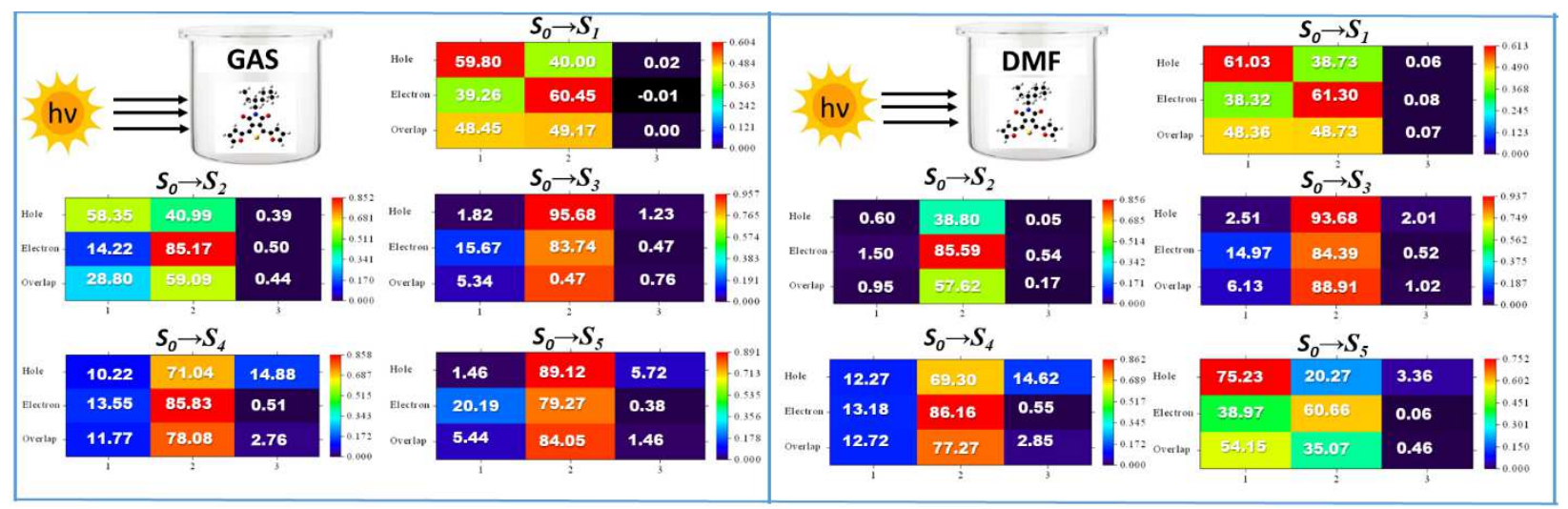

Fig. 8. Plotted heat maps of FTPF in gas and DMF generated with TD-SCF CAM-B3LYP method at 6-31+G(d,p) basis set.

For $S_{0} \rightarrow S_{1}, 59.80 \%$ and $40.00 \%$ of holes are domiciled on fragment 1 (two furanyl donors) and fragment 2 (pyrroledione acceptor) during excitation in gas phase, showing that before excitation, a high percentage of the subsequently excited electrons were concentrated on the donor $(59.8 \%)$ groups and some (40.00 $\%)$ around the acceptor. After excitation, a high volume of electrons is now domiciled on the acceptor $(60.45 \%)$, while $39.26 \%$ is now located on the donor groups. Overlap of hole and electrons significantly occurred on both the D (48.45\%) and A groups (49.17\%), because both shared appreciable amount of hole and electron during $S_{0} \rightarrow S_{1}$ excitation. It is conspicuous that $S_{0} \rightarrow S_{1}$ excitation in DMF share same heat map properties as in gas phase.

Before $S_{0} \rightarrow S_{1}$ excitation in gas phase, the excited electrons were concentrated on the donor groups, with few on the acceptor. It is evident from Fig. 8., that majority of these electrons moved to the acceptor $(85.17 \%)$ during excitation, $S_{0} \rightarrow S_{2}$ is a perfect D-A excitation interaction of a conjugated system, were electrons are transferred from the donor to acceptor. Although, for $S_{0} \rightarrow S_{2}$ excitation in DMF, the excitation electrons were domiciled on the acceptor group (38.80\%) before excitation, this quantity of electrons on the acceptor increased after the excitation process to $85.59 \%$. The hole and electron overlap on pyrroledione acceptor are approximately $58 \%$ for $S_{0} \rightarrow S_{2}$. It is important to note that fragment 3 (ethylhexyl group) had no significant contribution to hole and electron for all studied excitations in gas phase and DMF.

The excited electrons were located on the acceptor before $S_{0} \rightarrow S_{3}$ excitation in both DMF (93.68 $\%)$ and gas $(95.68 \%)$ phase, these electrons are insignificantly lost to the donors during excitation, leaving a high concentration of electron on the acceptor in both phases. This assured that a high overlap of hole and electron is located on the acceptor for $S_{0} \rightarrow S_{3}$ excitation in both gas $(88.51 \%)$ and DMF $(88.91 \%)$ phases. 
The acceptor unit exhibited the highest contributions to hole, electron, and hole-electron overlap for $S_{0} \rightarrow S_{4}$ in both phases as in $S_{0} \rightarrow S_{3}$, the hole concentration on the acceptor (hence the concentration of electron before excitation) is $71.04 \%$ and $69.30 \%$ in gas and DMF, respectively. This electron density improved during $S_{0} \rightarrow S_{4}$ excitation to $85.83 \%$ (gas) and $86.16 \%$ (DMF), while hole-electron overlap is valued at $78.08 \%$ (gas) and $77.27 \%$ (DMF) on the acceptor group. One can conclude that $S_{0} \rightarrow S_{3}$ and $S_{0} \rightarrow S_{4}$ are basically excitations around the pyrroledione acceptor group.

A major difference is observed in the $S_{0} \rightarrow S_{5}$ excitation of FTPF in gas and DMF phases, which correlates with the results from hole and electron indices results in Fig. 4. In gas phase; hole (89.12\%), electron $(79.27 \%)$ and hole-electron overlap (84.05\%) are all domiciled on the acceptor, like in $S_{0} \rightarrow S_{3}$ and $S_{0} \rightarrow S_{4}$ excitations, hence same inference can be drawn. In DMF, the hole is highly concentrated on the donor $(75.23 \%)$, while the electrons are mostly located on the acceptor after $S_{0} \rightarrow S_{5}$ excitation. A better overlap of hole-electron is located on the donor (54.14\%) during excitation, than around the acceptor $(35.07 \%)$. It is important to note that before the excitations in FTPF, the excitation electrons were domiciled on the two furanyl donors, this electron density shifted to the acceptor after the first $\left(S_{0} \rightarrow S_{1}\right)$ excitation. Other excitations virtually involved the transition of electrons within the acceptor moiety, but the $S_{0} \rightarrow S_{5}$ in DMF, where the excitation electrons originated from the donor group like in $S_{0} \rightarrow S_{1}$. From the visualized heat maps in Fig. 8., the colour distribution on heat map for $S_{0} \rightarrow S_{1}, S_{0} \rightarrow S_{3}$ and $S_{0} \rightarrow S_{4}$ in gas and DMF are respectively equivalent, which suggest a possible equivalent domicile for hole and electron.

\subsection{Photovoltaic Properties}

The open circuit voltage $\left(V_{O C}\right)$ is defined as the energy difference between the redox potential of the electrolyte's redox couple $\left(I^{-} / I_{3}^{-}\right)$and the quasi-Fermi level of the semiconductor's conduction band $\left(\mathrm{TiO}_{2}\right)$. It is mathematically represented as:

$$
V_{O C}=\frac{E_{C B}+\Delta C B}{q}+\frac{k T}{q} \operatorname{In}\left(\frac{n_{c}}{N_{C B}}\right)-\frac{E_{R e d o x}}{q}
$$

Where, $E_{C B}$ is the conduction band edge of $\mathrm{TiO}_{2}$, $\mathrm{q}$ is the unit charge, $\mathrm{T}$ is the absolute temperature, $\mathrm{k}$ is the Boltzmann constant, $n_{c}$ is the number of electrons in the conduction band, $N_{C B}$ is the density of accessible states in the conduction band and $E_{\text {redox }}$ is the redox potential of the electrolyte. $\Delta \mathrm{CB}$ is the shift of CB when the dyes are adsorbed $[69,70]$. It is mathematically represented as:

$$
\Delta C B=\frac{q \mu_{\text {normal }} \gamma}{\varepsilon_{0} \varepsilon}
$$


Where $\mu_{\text {normal }}$ is the dipole moment of the individual dye molecule perpendicular to the surface of $\mathrm{TiO}_{2}$, and $\gamma$ is the dye surface concentration, $\varepsilon_{0}$ and $\varepsilon$ are the vacuum permittivity and dielectric permittivity, respectively. The value of $V_{O C}$ can also be approximately obtained from the difference between $E_{L U M O}$ and $E_{C B}$. It is used for this purpose because the studied monomer system is singly not in the adsorbed state on $\mathrm{TiO}_{2}[70]$.

$J_{s c}$ can be mathematically expressed as:

$$
J_{S C}=\int L H E(\lambda) \phi_{\text {inject }} \eta_{\text {collect }} d \lambda
$$

LHE $(\lambda)$ is the light harvesting efficiency at maximum wavelength, $\phi_{\text {inject }}$ is the electron injection efficiency, and $\eta_{\text {collect }}$ is the charge collection efficiency. To obtain a high $J_{S C}$, LHE and $\phi_{\text {inject }}$ should be as high as possible. The LHE can be mathematically expressed as:

$$
L H E=1-10^{-f}
$$

Where $\mathrm{f}$ is the oscillator strength of the dye corresponding to $\lambda_{\max }$, $\phi_{\text {inject }}$ is related to the thermodynamic driving force $\Delta G_{\text {inject }}$ of electron injection from the excited states of dye to conductive band $\mathrm{TiO}_{2}$

$\Delta G_{\text {inject }}$ (The free energy difference for electron injection) is mathematically represented as:

$$
\Delta G_{\text {inject }}=E^{d y e *}-E_{C B}^{\mathrm{TiO}_{2}} \approx E^{d y e}+\Delta E-E_{C B}^{\mathrm{TiO}_{2}}
$$

Where $E^{d y e *}$ is the redox potential of the oxidized dye at excited state. $E^{d y e}$ is the redox potential of the oxidized dye at ground state and $\Delta E$ is the lowest vertical excitation energy. $E_{C B}^{\mathrm{TiO}_{2}}$ is the energy of the conductive band edge of $\mathrm{TiO}_{2}[69-72]$.

$\Delta G_{r e g}$ (The driving force for dye regeneration) is mathematically represented as:

$\Delta G_{r e g}=\mu\left(I^{-} / I_{3}^{-}\right)-E^{d y e}$

A value of $\Delta G_{r e g}$ greater than $0.2 \mathrm{eV}$ for an oxidized dye could be the efficient electron injection.

To determine the value of $J_{s c}$ and the overall potential conversion efficiency $(\mu)$, the calculated values of open circuit voltage $(V o c)$, the oscillator strength $\mathrm{f}$, Light harvesting efficiency (LHE), $\lambda_{\max }$, the force energy difference for electron injection $\left(\triangle G^{\text {ing }}\right)$, the driving forces of regeneration $\left(\triangle G^{\text {reg }}\right)$ were calculated in Gas, Hexane, DMF, and THF phases as presented in the Table 7., it is worthy to note that a conjugated system with little energy band gap is beneficial to a red- shifted absorption spectrum and give rise to more 
electrons corresponding to an increase in $\mathrm{n}_{\mathrm{c}}$ and thus, increase the efficiency of $V_{o c}$. In this study, it was observed that in all the solvent, $\triangle G^{\text {inj }}$ is greater than $0.2 \mathrm{eV}$ and therefore, FTPF monomer in the four phases provide efficient electron injection. However, $\triangle G^{\text {inj }}$ values for DMF and THF are larger than in other phases, this implies that both solvents ensure provision of highest electron injection in FTPF monomer system. It is also observed that the $\Delta G^{\text {reg }}$ is greater than 0.4 in all the phases and at all the excitation hence; an implication that DMF and THF have more effect on $\triangle \mathrm{G}^{\mathrm{reg}}$ compared to the other studied solvents. Results in Table 7., shows that among the studied phases, the highest $f$ value comes from DMF and THF in the vertical excitation which could be accounted on the basis of solvent polarity. Also its was observed that the LHE varies in different phases and show greater stability in the first and second excitation state for both phases. The highest values of Voc were obtained in Hexane and DMF.

Table 7. Photovoltaic Properties, oscillator strength, and excitation energies of FTPF in Gas, Hexane, DMF and THF phases calculated at TD-SCF/B3LYP/6-31+G(d,p)

\begin{tabular}{llllllllll}
\hline Phases & Excitation & $\mathbf{L H E} / \mathbf{e V}$ & $\Delta \mathbf{G}^{\text {inj}} / \mathbf{e V}$ & $\boldsymbol{f}$ & $\mathbf{E} / \mathbf{e V}$ & $\mathbf{J}_{\text {sc }}$ & $\mathbf{V}_{\text {oc }}$ & $\Delta \mathbf{G}^{\text {reg }}$ & $\Delta \mathbf{G}_{\mathbf{c r}}$ \\
\hline Gas & $\mathrm{S}_{\mathrm{o}} \rightarrow \mathrm{S}_{1}$ & 0.78 & 2.74 & 0.66 & 3.48 & 2.14 & 1.67 & 2.47 & 4.92 \\
Hexane & $\mathrm{S}_{\mathrm{o}} \rightarrow \mathrm{S}_{1}$ & 0.84 & 2.80 & 0.79 & 3.35 & 2.35 & 2.80 & 3.40 & 6.05 \\
DMF & $\mathrm{S}_{\mathrm{o}} \rightarrow \mathrm{S}_{1}$ & 0.84 & 2.82 & 0.81 & 3.32 & 2.37 & 2.81 & 3.61 & 6.06 \\
THF & $\mathrm{S}_{\mathrm{o}} \rightarrow \mathrm{S}_{1}$ & 0.84 & 2.82 & 0.80 & 3.34 & 2.37 & 2.70 & 3.50 & 5.95 \\
& & & & & & & & & \\
Gas & $\mathrm{S}_{\mathrm{o}} \rightarrow \mathrm{S}_{2}$ & 0.39 & 2.74 & 0.21 & 3.71 & 1.07 & 1.67 & 2.77 & 4.92 \\
Hexane & $\mathrm{S}_{\mathrm{o}} \rightarrow \mathrm{S}_{2}$ & 0.46 & 2.80 & 3.62 & 0.27 & 1.29 & 2.80 & 3.40 & 6.05 \\
DMF & $\mathrm{S}_{\mathrm{o}} \rightarrow \mathrm{S}_{2}$ & 0.47 & 2.82 & 0.27 & 3.60 & 1.32 & 2.81 & 3.61 & 1.32 \\
THF & $\mathrm{S}_{\mathrm{o}} \rightarrow \mathrm{S}_{2}$ & 0.47 & 2.80 & 0.27 & 3.61 & 1.33 & 2.70 & 3.50 & 2.82 \\
& & & & & & & & & \\
Gas & $\mathrm{S}_{\mathrm{o}} \rightarrow \mathrm{S}_{3}$ & 0.00 & 2.74 & 0.00 & 4.46 & 0.00 & 1.67 & 2.47 & 4.92 \\
Hexane & $\mathrm{S}_{\mathrm{o}} \rightarrow \mathrm{S}_{3}$ & 0.00 & 2.80 & 4.47 & 0.00 & 0.00 & 2.80 & 3.40 & 6.05 \\
DMF & $\mathrm{S}_{\mathrm{o}} \rightarrow \mathrm{S}_{3}$ & 0.00 & 2.82 & 0.01 & 4.53 & 0.00 & 2.81 & 3.61 & 6.06 \\
THF & $\mathrm{S}_{\mathrm{o}} \rightarrow \mathrm{S}_{3}$ & 0.00 & 2.82 & 0.00 & 4.50 & 0.00 & 2.70 & 3.50 & 5.95 \\
& & & & & & & & & \\
Gas & $\mathrm{S}_{\mathrm{o}} \rightarrow \mathrm{S}_{4}$ & 0.02 & 2.82 & 0.01 & 4.60 & 0.04 & 1.67 & 2.47 & 4.92 \\
Hexane & $\mathrm{S}_{\mathrm{o}} \rightarrow \mathrm{S}_{4}$ & 0.02 & 2.80 & 0.01 & 4.57 & 0.06 & 2.80 & 3.40 & 6.05 \\
DMF & $\mathrm{S}_{\mathrm{o}} \rightarrow \mathrm{S}_{4}$ & 0.03 & 2.82 & 0.01 & 4.50 & 0.08 & 2.81 & 3.61 & 6.06 \\
THF & $\mathrm{S}_{\mathrm{o}} \rightarrow \mathrm{S}_{4}$ & 0.03 & 2.82 & 0.01 & 4.53 & 0.08 & 2.70 & 3.50 & 5.95 \\
Gas & $\mathrm{S}_{\mathrm{o}} \rightarrow \mathrm{S}_{5}$ & 0.00 & 2.74 & 0.00 & 4.77 & 0.00 & 1.67 & 2.47 & 4.92 \\
Hexane & $\mathrm{S}_{\mathrm{o}} \rightarrow \mathrm{S}_{5}$ & 0.00 & 2.80 & 0.00 & 4.57 & 0.00 & 2.80 & 3.40 & 6.05 \\
DMF & $\mathrm{S}_{\mathrm{o}} \rightarrow \mathrm{S}_{5}$ & 0.30 & 2.82 & 0.16 & 4.77 & 0.85 & 2.81 & 3.61 & 6.06 \\
THF & $\mathrm{S}_{\mathrm{o}} \rightarrow \mathrm{S}_{5}$ & 0.42 & 2.82 & 0.15 & 4.78 & 1.18 & 2.70 & 3.50 & 5.95 \\
\hline
\end{tabular}




\subsection{Natural Bonding Orbital (NBO) Analysis}

The major stabilization energies of FTPF monomer was analyzed using natural bonding orbital analysis. NBO studies afford us with the nature of donor and virtual acceptor orbitals, the interaction between them and their occupancies. These interactions exist through the delocalization of mobile electrons from occupied Lewis orbitals to vacant (virtual) non-Lewis molecular orbitals to improve the presence of electrons, hence the occupancies [22, 73-74]. The magnitude of the interactions between molecular orbitals contributes fractionally to the overall stability of the molecule. Various donors and acceptor orbitals interactions were considered in this study, with respect to their energy $\left(E^{2}\right)$ contribution. Results for the second order perturbation energies of the donor molecular orbitals and virtual acceptor orbitals from NBO analysis are published in Table 8.

Table 8. Second Order Perturbation Energies of FTPF from NBO Analysis generated with B3LYP method at $6-31+\mathrm{G}(\mathrm{d}, \mathrm{p})$ basis set.

\begin{tabular}{|c|c|c|c|c|c|c|}
\hline Donor & Occupancy & Acceptor & Occupancy & $\begin{array}{c}\mathbf{E}^{2} \\
(\mathrm{kcal} / \mathrm{mol})\end{array}$ & $\begin{array}{c}\mathbf{E}(\mathbf{J})-\mathbf{E}(\mathbf{i}) \\
(\text { a.u) }\end{array}$ & $\begin{array}{l}\mathbf{F}(\mathbf{j} . \mathbf{i}) \\
\text { (a.u) }\end{array}$ \\
\hline \multirow[t]{2}{*}{$\pi \mathrm{C}_{1}-\mathrm{O}_{27}$} & 1.97400 & $\sigma^{*} \mathrm{C}_{22}-\mathrm{H}_{32}$ & 0.01468 & 201.89 & 0.10 & 0.126 \\
\hline & & $\sigma^{*} \mathrm{C}_{23}-\mathrm{H}_{29}$ & 0.00772 & 21.64 & 2.25 & 0.198 \\
\hline$\pi \mathrm{C}_{2}-\mathrm{C}_{6}$ & 1.76312 & $\pi^{*} \mathrm{C}_{1}-\mathrm{O}_{27}$ & 0.29135 & 18.44 & 0.29 & 0.066 \\
\hline \multirow[t]{2}{*}{$\sigma \mathrm{C}_{3}-\mathrm{C}_{4}$} & 1.96992 & $\sigma^{*} \mathrm{C}_{22}-\mathrm{H}_{32}$ & 0.01468 & 68.54 & 0.41 & 0.149 \\
\hline & & $\pi^{*} \mathrm{C}_{23}-\mathrm{H}_{29}$ & 0.00772 & 24.79 & 2.56 & 0.226 \\
\hline \multirow[t]{3}{*}{$\pi \mathrm{C}_{3}-\mathrm{C}_{7}$} & 1.76325 & $\pi * \mathrm{C}_{2}-\mathrm{C}_{6}$ & 0.39324 & 16.30 & 0.29 & 0.064 \\
\hline & & $\pi^{*} \mathrm{C}_{4}-\mathrm{O}_{26}$ & 0.29001 & 18.44 & 0.29 & 0.066 \\
\hline & & $\pi * \mathrm{C}_{12}-\mathrm{C}_{13}$ & 0.32255 & 13.42 & 0.31 & 0.059 \\
\hline$\sigma \mathrm{N}_{5}-\mathrm{C}_{16}$ & 1.98638 & $\sigma^{*} \mathrm{C}_{22}-\mathrm{H}_{32}$ & 0.01468 & 12.04 & 0.44 & 0.065 \\
\hline \multirow[t]{2}{*}{$\pi \mathrm{C}_{8}-\mathrm{C}_{9}$} & & $\pi^{*} \mathrm{C}_{2}-\mathrm{C}_{6}$ & 0.39324 & 17.05 & 0.28 & 0.064 \\
\hline & & $\pi^{*} \mathrm{C}_{10}-\mathrm{C}_{11}$ & 0.26717 & 16.42 & 0.29 & 0.062 \\
\hline \multirow[t]{2}{*}{$\sigma \mathrm{C}_{8}-\mathrm{O}_{24}$} & 1.98878 & $\sigma^{*} \mathrm{C}_{11}-\mathrm{H}_{51}$ & 0.01344 & 50.07 & 0.08 & 0.058 \\
\hline & & $\sigma^{*} \mathrm{C}_{12}-\mathrm{H}_{13}$ & 0.02100 & 264.38 & 0.03 & 0.084 \\
\hline \multirow[t]{2}{*}{$\sigma \mathrm{C}_{9}-\mathrm{H}_{49}$} & 1.97900 & $\sigma^{*} \mathrm{C}_{22}-\mathrm{H}_{32}$ & 0.01468 & 39.92 & 0.24 & 0.088 \\
\hline & & $\sigma^{*} \mathrm{C}_{23}-\mathrm{H}_{29}$ & 0.00772 & 10.74 & 2.39 & 0.144 \\
\hline \multirow{2}{*}{$\sigma \mathrm{C}_{10}-\mathrm{C}_{11}$} & 1.98743 & $\sigma^{*} \mathrm{C}_{22}-\mathrm{H}_{32}$ & 0.01468 & 297.11 & 0.52 & 0.350 \\
\hline & & $\sigma^{*} \mathrm{C}_{23}-\mathrm{H}_{29}$ & 0.00772 & 194.10 & 2.67 & 0.643 \\
\hline \multirow[t]{2}{*}{$\sigma \mathrm{C}_{10}-\mathrm{H}_{50}$} & 1.98272 & $\sigma^{*} \mathrm{C}_{22}-\mathrm{H}_{32}$ & 0.01468 & 120.02 & 0.25 & 0.154 \\
\hline & & $\sigma^{*} \mathrm{C}_{23}-\mathrm{H}_{29}$ & 0.00772 & 14.48 & 2.40 & 0.167 \\
\hline \multirow[t]{4}{*}{$\sigma \mathrm{C}_{11}-\mathrm{O}_{24}$} & 1.98984 & $\sigma^{*} \mathrm{C}_{11}-\mathrm{H}_{51}$ & 0.01344 & 726.09 & 0.14 & 0.285 \\
\hline & & $\sigma^{*} \mathrm{C}_{22}-\mathrm{H}_{32}$ & 0.01468 & 149.04 & 0.65 & 0.279 \\
\hline & & $\sigma^{*} \mathrm{C}_{22}-\mathrm{H}_{33}$ & 0.01117 & 8022.80 & 0.09 & 0.756 \\
\hline & & $\sigma^{*} \mathrm{C}_{23}-\mathrm{H}_{29}$ & 0.00772 & 126.57 & 2.80 & 0.532 \\
\hline$\sigma \mathrm{C}_{11}-\mathrm{H}_{51}$ & 1.98610 & $\sigma^{*} \mathrm{C}_{23}-\mathrm{H}_{29}$ & 0.00772 & 194.10 & 2.00 & 0.557 \\
\hline$\sigma \mathrm{C}_{12}-\mathrm{C}_{13}$ & 1.97716 & $\sigma^{*} \mathrm{C}_{22}-\mathrm{H}_{32}$ & 0.01468 & 78.94 & 0.44 & 0.167 \\
\hline$\sigma \mathrm{C}_{18}-\mathrm{C}_{19}$ & 1.99118 & $\sigma^{*} \mathrm{C}_{22}-\mathrm{H}_{32}$ & 0.01468 & 98.59 & 0.29 & 0.152 \\
\hline \multirow[t]{2}{*}{$\sigma \mathrm{C}_{19}-\mathrm{H}_{38}$} & 1.99026 & $\sigma^{*} \mathrm{C}_{22}-\mathrm{H}_{32}$ & 0.01468 & 469.50 & 0.28 & 0.322 \\
\hline & & $\sigma^{*} \mathrm{C}_{23}-\mathrm{H}_{29}$ & 0.00772 & 102.19 & 2.43 & 0.445 \\
\hline$\sigma \mathrm{C}_{23}-\mathrm{H}_{30}$ & 1.99068 & $\sigma^{*} \mathrm{C}_{22}-\mathrm{H}_{32}$ & 0.01468 & 164.02 & 0.20 & 0.164 \\
\hline $\mathrm{LP} \mathrm{N}_{5}$ & 1.61771 & $\pi^{*} \mathrm{C}_{1}-\mathrm{O}_{27}$ & 0.29135 & 53.34 & 0.26 & 0.108 \\
\hline
\end{tabular}




\begin{tabular}{ccccccc}
\hline & \multirow{2}{*}{1.96986} & $\pi^{*} \mathrm{C}_{4}-\mathrm{O}_{26}$ & 0.29001 & 52.88 & 0.26 & 0.108 \\
$\mathrm{LP} \mathrm{O}_{24}$ & & $\sigma^{*} \mathrm{C}_{22}-\mathrm{H}_{32}$ & 0.01468 & 492.76 & 0.09 & 0.201 \\
& & $\sigma^{*} \mathrm{C}_{23}-\mathrm{H}_{29}$ & 0.00772 & 47.17 & 2.24 & 0.313 \\
& & $\pi^{*} \mathrm{C}_{8}-\mathrm{C}_{9}$ & 0.32257 & 23.55 & 0.41 & 0.089 \\
& \multirow{2}{*}{1.96989} & $\pi^{*} \mathrm{C}_{10}-\mathrm{C}_{11}$ & 0.26717 & 23.76 & 0.41 & 0.088 \\
& & $\sigma^{*} \mathrm{C}_{22}-\mathrm{H}_{32}$ & 0.01468 & 408.92 & 0.46 & 0.389 \\
$\mathrm{LP} \mathrm{O}_{25}$ & \multirow{2}{*}{1.97458} & $\sigma^{*} \mathrm{C}_{23}-\mathrm{H}_{29}$ & 0.00772 & 151.49 & 2.61 & 0.565 \\
& & $\sigma^{*} \mathrm{C}_{22}-\mathrm{H}_{32}$ & 0.01468 & 2249.25 & 0.08 & 0.385 \\
$\mathrm{LP} \mathrm{O}_{27}$ & \multirow{2}{*}{1.97374} & $\sigma^{*} \mathrm{C}_{23}-\mathrm{H}_{29}$ & 0.00772 & 127.87 & 2.23 & 0.493 \\
& & $\sigma^{*} \mathrm{C}_{23}-\mathrm{H}_{29}$ & 0.00772 & 29.55 & 2.14 & 0.232 \\
& & $\sigma^{*} \mathrm{C}_{1}-\mathrm{C}_{2}$ & 0.07111 & 19.74 & 0.73 & 0.109 \\
$\mathrm{LP} \mathrm{S}_{28}$ & \multirow{2}{*}{1.98606} & $\sigma^{*} \mathrm{C}_{1}-\mathrm{N}_{5}$ & 0.08937 & 28.00 & 0.69 & 0.125 \\
& & $\pi^{*} \mathrm{C}_{2}-\mathrm{C}_{6}$ & 0.39324 & 20.54 & 0.27 & 0.067 \\
$\pi^{*} \mathrm{C}_{2}-\mathrm{C}_{6}$ & 0.39324 & $\pi^{*} \mathrm{C}_{3}-\mathrm{C}_{7}$ & 0.39313 & 20.55 & 0.27 & 0.067 \\
$\pi^{*} \mathrm{C}_{3}-\mathrm{C}_{7}$ & 0.39313 & $\pi^{*} \mathrm{C}_{8}-\mathrm{C}_{9}$ & 0.32257 & 182.43 & 0.01 & 0.075 \\
\hline
\end{tabular}

Interaction between the non-bonding loan pair (LP) of electron on the heteroatoms and the sigma and pi antibonding orbitals $\left(\sigma^{*}\right.$ and $\left.\pi^{*}\right)$ contributed immensely to the stabilization of the studied D-A-D monomer. Most significant are the interactions; LP O ${ }_{24} \rightarrow \sigma^{*} \mathrm{C}_{22}-\mathrm{H}_{32}\left(\mathrm{E}^{2}=492.76 \mathrm{kcal} / \mathrm{mol}\right), \mathrm{LP} \mathrm{O}_{25} \rightarrow$ $\sigma^{*} \mathrm{C}_{22}-\mathrm{H}_{32}\left(\mathrm{E}^{2}=408.92 \mathrm{kcal} / \mathrm{mol}\right) / \sigma^{*} \mathrm{C}_{23}-\mathrm{H} 29\left(\mathrm{E}^{2}=151.49 \mathrm{kcal} / \mathrm{mol}\right)$, originating from the furanyl donors, and $\mathrm{LP} \mathrm{O}_{26} \rightarrow \sigma^{*} \mathrm{C}_{22}-\mathrm{H}_{32}\left(\mathrm{E}^{2}=2249.25 \mathrm{kcal} / \mathrm{mol}\right) / \sigma^{*} \mathrm{C}_{23}-\mathrm{H}_{29}\left(\mathrm{E}^{2}=127.87 \mathrm{kcal} / \mathrm{mol}\right)$, LP $\mathrm{O}_{27} \rightarrow \sigma^{*} \mathrm{C}_{23}-\mathrm{H}_{29}\left(\mathrm{E}^{2}=29.55 \mathrm{kcal} / \mathrm{mol}\right) / \sigma^{*} \mathrm{C}_{1}-\mathrm{N}_{5}\left(\mathrm{E}^{2}=28.00 \mathrm{kcal} / \mathrm{mol}\right), \mathrm{LP} \mathrm{S}_{28} \rightarrow \pi^{*} \mathrm{C}_{2}-\mathrm{C}_{6}\left(\mathrm{E}^{2}=20.54\right.$ $\mathrm{kcal} / \mathrm{mol}) / \pi^{*} \mathrm{C}_{3}-\mathrm{C}_{7}\left(\mathrm{E}^{2}=20.55 \mathrm{kcal} / \mathrm{mol}\right), \mathrm{LP} \mathrm{N} \rightarrow \pi^{*} \mathrm{C}_{1}-\mathrm{O}_{27}\left(\mathrm{E}^{2}=53.34 \mathrm{kcal} / \mathrm{mol}\right) / \pi^{*} \mathrm{C}_{4}-\mathrm{O}_{26}\left(\mathrm{E}^{2}=\right.$ $52.88 \mathrm{kcal} / \mathrm{mol})$, around the acceptor fragment.

Other interactions $\left(\sigma / \pi \rightarrow \sigma^{*} / \pi^{*}\right)$ occur in hyper-conjugated systems to ensure resonance stability on the molecule [73]. $\pi \mathrm{C}_{1}-\mathrm{O}_{27}$ (with occupancy; 1.9740) donated electron densities to $\sigma^{*} \mathrm{C}_{22}-\mathrm{H}_{32}\left(\mathrm{E}^{2}=\right.$ $201.89 \mathrm{kcal} / \mathrm{mol})$ and $\sigma^{*} \mathrm{C}_{23}-\mathrm{H}_{29}\left(\mathrm{E}^{2}=21.64 \mathrm{kcal} / \mathrm{mol}\right), \sigma \mathrm{C}_{3}-\mathrm{C}_{4} \rightarrow \sigma^{*} \mathrm{C}_{22}-\mathrm{H}_{32}\left(\mathrm{E}^{2}=68.54 \mathrm{kcal} / \mathrm{mol}\right)$, $\sigma \mathrm{N}_{5}-\mathrm{C}_{16} \rightarrow \sigma^{*} \mathrm{C}_{22}-\mathrm{H}_{32}\left(\mathrm{E}^{2}=12.04 \mathrm{kcal} / \mathrm{mol}\right)$, these interaction offers a connection between the highly conjugated pyrroledione acceptor and the substituted ethylhexyl moiety. Also, inter-fragment delocalization between the acceptor and donors exist, very significant ones are; $\sigma \mathrm{C}_{8}-\mathrm{O}_{24} \rightarrow \sigma^{*} \mathrm{C}_{12}-\mathrm{H}_{13}$ $\left(\mathrm{E}^{2}=264.38 \mathrm{kcal} / \mathrm{mol}\right)$, and back-donations $\left(\pi^{*} \rightarrow \pi^{*}\right)$ from acceptor to donor; $\pi^{*} \mathrm{C}_{2}-\mathrm{C}_{6} \rightarrow \pi^{*} \mathrm{C}_{8}-\mathrm{C}_{9}\left(\mathrm{E}^{2}\right.$ $=182.43 \mathrm{kcal} / \mathrm{mol}), \pi^{*} \mathrm{C}_{3}-\mathrm{C}_{7} \rightarrow \pi^{*} \mathrm{C}_{12}-\mathrm{C}_{13}\left(\mathrm{E}^{2}=182.71 \mathrm{kcal} / \mathrm{mol}\right)$. High energies were recorded for some intra-fragment (within donor) and inter-fragment (between D-A-D and ethylhexyl group) interactions; $\sigma \mathrm{C}_{11}-\mathrm{O}_{24} \rightarrow \sigma^{*} \mathrm{C}_{11}-\mathrm{H}_{51}\left(\mathrm{E}^{2}=726.09 \mathrm{kcal} / \mathrm{mol}\right) / \sigma^{*} \mathrm{C}_{22}-\mathrm{H}_{32}\left(\mathrm{E}^{2}=149.04 \mathrm{kcal} / \mathrm{mol}\right) / \sigma^{*} \mathrm{C}_{22}-$ $\mathrm{H}_{33}\left(\mathrm{E}^{2}=8022.80 \mathrm{kcal} / \mathrm{mol}\right) / \sigma^{*} \mathrm{C}_{23}-\mathrm{H}_{29}\left(\mathrm{E}^{2}=126.57 \mathrm{kcal} / \mathrm{mol}\right)$, a major contributor to the stability of the D-A-D monomer system. 


\subsection{CONCLUSION}

We studied the spectra and excitation properties of FTPF monomer in gas, hexane, DMF and THF phases, using DFT and TD-DFT approach. A dual absorption was recorded for FTPF in DMF and THF, corresponding to $n \rightarrow \pi^{*}$ and $\pi \rightarrow \pi^{*}$ transitions, this correlates to the experimental results. Although, a single $\left(\pi \rightarrow \pi^{*}\right)$ absorption occurred in gas and hexane phase. We conclude that FTPF experience more excitations in polar (DMF and THF) than non-polar (gas and hexane) solvents, a major red shift was also observed as we move from gas/hexane to polar DMF/THF. From FMO, we discovered that the calculated energy gap of FTPF is very low, and is close to the values obtained experimentally by Çakal et al, a good opto-electronic property required for organic cells. Little or no solvent effect was recorded in the DOS and STM results. Isosurface values on ESP plots showed that decrease in the distribution of electron densities around FTPF monomer follows the trend $\mathrm{O}>\mathrm{N}>\mathrm{S}$. ADCH analysis exposed the best sites for electrophilic substitution reactions are the carbonyl oxygen atoms of the acceptor fragment and the terminal carbon atoms of the ethylhexyl substituents.

We analyzed the hole-electron excitations for the first 5 excitations, for good understanding about the intramolecular electronic transitions in FTPF monomer. $S_{0} \rightarrow S_{1}$ is a delocalized $\pi \rightarrow \pi^{*}$ Rydberg excitations originating from the $\mathrm{C}=\mathrm{C} \pi$ bonds within the D-A-D system. A LE was observed for $S_{0} \rightarrow S_{2}$, while $S_{0} \rightarrow S_{3}$ in water occurred as an $\mathrm{n} \rightarrow \pi^{*}$ from the carbonyl and azolide groups of the acceptor unit. $S_{0} \rightarrow S_{3}$ was observed to be $n \rightarrow \pi^{*}$ charge transfer originating from the carbonyl oxygen atoms in DMF. $S_{0} \rightarrow S_{5}$ in water and $S_{0} \rightarrow S_{4}$ are $\mathrm{n} \rightarrow \pi^{*}$ LE type excitations, while $S_{0} \rightarrow S_{5}$ in DMF conformed to a delocalized $\pi \rightarrow \pi^{*}$ excitation extended over the D-A-D conjugated backbone. The obtained photovoltaic properties suggest that FTPF provides efficient electron injection in all solvents, although best properties are observed in DMF and THF phases. NBO analysis results showed that there exists high contribution from several intra- and inter-fragment electron delocalizations that contribute immensely to the stabilization energy of FTPF monomer. In summary, FTPF is an adequate D-A-D monomer for an optoelectrically active polymer applicable in organic photovoltaics.

\section{Acknowledgement}

The authors appreciate our colleagues in the Computational and Bio-simulation Research Group, University of Calabar, Nigeria. Also, Enudi O.C acknowledges all our colleagues in the Department of Chemistry, University of Ibadan for their respective inputs to the success of this project.

\section{Funding}

This research received no funding from any Governmental or Non-Governmental Institution.

\section{Conflicts of Interest}


The authors declare no conflict of interest.

\section{Ethics Approval}

Not applicable

\section{Consent to Participate}

Not applicable

\section{Consent for Publication}

Not applicable

\section{Availability of Data and Material}

Data are available with the authors. They will be released on request.

\section{Code Availability}

Not applicable

\section{Author's Contributions}

OE co-designed this work, carried out the optimization, and energy calculations, excitation studies, and wrote part of this paper. HL designed, supervised and revised this work, and provided software used. GO analyzed STM, DOS and IR spectroscopic and geometric properties. MK analyzed the FMO and MEP properties. PO analyzed the NBO and wrote part of this paper. TG carried out the photovoltaics analysis. IA and AP proofread this paper and AA analyzed the NMR spectroscopy data and wrote part of this work..

\section{REFERENCES}

[1] Campana, P. E., Landelius, T., Andersson, S., Lundström, L., Nordlander, E., He, T., ... \& Yan, J. (2020). A gridded optimization model for photovoltaic applications. Solar Energy, 202, 465-484.

[2] Farhat, A., Khera, R. A., Iqbal, S., \& Iqbal, J. (2020). Tuning the optoelectronic properties of Subphthalocyanine (SubPc) derivatives for photovoltaic applications. Optical Materials, 107, 110154.

[3] Jin, Z., Zhang, Z., Xiu, J., Song, H., Gatti, T., \& He, Z. (2020). A critical review on bismuth and antimony halide based perovskites and their derivatives for photovoltaic applications: recent advances and challenges. Journal of Materials Chemistry A, 8(32), 16166-16188.

[4] Ullah, S., Wang, J., Alvi, M. H., Chang, R., Yang, P., Liu, L., ... \& Chen, Y. (2021). Fabrication and characterization of lead-free Cs2SnI6 perovskite films for photovoltaic applications. International Journal of Energy Research, 45(2), 1720-1728.

[5] Saleem, M., Irshad, K., Ur Rehman, S., Javed, M. S., Hasan, M. A., Ali, H. M., ... \& Islam, S. (2021). Characteristics and Photovoltaic Applications of Au-Doped ZnO-Sm Nanoparticle Films. Nanomaterials, 11(3), 702.

[6] Ullah, S., Wang, J., Yang, P., Liu, L., Khan, J., Yang, S. E., ... \& Chen, Y. (2021). Lead-Free Cs2SnI6 Perovskites for Optoelectronic Applications: Recent Developments and Perspectives. Solar RRL, 5(5), 2000830. 
[7] Na, H. J., Lee, S. E., Lee, E. G., Lee, J. H., Gong, Y. J., Kim, H., ... \& Kim, Y. S. (2021). Nanometer-Thick Cs2SnI6 Perovskite-Polyethylene Glycol Dimethacrylate Composite Films for Highly Stable Broad-Band Photodetectors. ACS Applied Nano Materials, 4(5), 5309-5318.

[8] Shrivastava, P., Kavaipatti, B., \& Bhargava, P. (2021). First-principles study of Cs2Ti1- xMxBr6 $(\mathrm{M}=\mathrm{Pb}, \mathrm{Sn})$ and numerical simulation of the solar cells based on Cs2Ti0. $25 \mathrm{Sn} 0.75 \mathrm{Br} 6$ perovskite. International Journal of Energy Research, 45(5), 8049-8060.

[9] Lin, L., Jones, T. W., Yang, T. C. J., Duffy, N. W., Li, J., Zhao, L., ... \& Wilson, G. J. (2021). Inorganic Electron Transport Materials in Perovskite Solar Cells. Advanced Functional Materials, 31(5), 2008300.

[10] Ajayan, J., Nirmal, D., Mohankumar, P., Saravanan, M., Jagadesh, M., \& Arivazhagan, L. (2020). A review of photovoltaic performance of organic/inorganic solar cells for future renewable and sustainable energy technologies. Superlattices and Microstructures, 143, 106549.

[11] Lu, Z., Liu, X., Hou, G., Chen, J., Zhu, T., Xu, J., \& Chen, K. (2020). Doping-Free Titanium Nitride Carrier Selective Contacts for Efficient Organic-Inorganic Hybrid Solar Cells. ACS Applied Energy Materials, 3(9), 9208-9215.

[12] Jiang, K., Wang, J., Wu, F., Xue, Q., Yao, Q., Zhang, J., ... \& Yip, H. L. (2020). Dopant-free organic hole-transporting material for efficient and stable inverted all-inorganic and hybrid perovskite solar cells. Advanced Materials, 32(16), 1908011.

[13] Cui, Y., Hong, L., \& Hou, J. (2020). Organic photovoltaic cells for indoor applications: opportunities and challenges. ACS Applied Materials \& Interfaces, 12(35), 38815-38828.

[14] Wang, X., Sun, Q., Gao, J., Ma, X., Son, J. H., Jeong, S. Y., ... \& Zhang, F. (2021). Ternary organic photovoltaic cells exhibiting $17.59 \%$ efficiency with two compatible Y6 derivations as acceptor. Solar Rrl, 5(3), 2100007.

[15] Devižis, A., Gelzinis, A., Chmeliov, J., Diethelm, M., Endriukaitis, L., Padula, D., \& Hany, R. (2021). Carrier Tunneling from Charge Transfer States in Organic Photovoltaic Cells. Advanced Functional Materials, 2102000.

[16] Zhao, C., Tang, C. G., Seah, Z. L., Koh, Q. M., Chua, L. L., Png, R. Q., \& Ho, P. K. (2021). Improving organic photovoltaic cells by forcing electrode work function well beyond onset of Ohmic transition. Nature communications, 12(1), 1-9.

[17] Cattin, L., Louarn, G., Morsli, M., \& Bernède, J. C. (2021). Semi-transparent organic photovoltaic cells with dielectric/metal/dielectric top electrode: Influence of the metal on their performances. Nanomaterials, 11(2), 393.

[18] Yang, L., Zhu, Y., Liu, J., Chen, Y., Wu, J., Pang, Z., ... \& Huang, Y. (2021). Marked effects of azulenyl vs. naphthyl groups on donor- $\pi$-acceptor- $\pi$-donor small molecules for organic photovoltaic cells. Dyes and Pigments, 187, 109079.

[19] Xu, Y., Yao, H., Ma, L., Wu, Z., Cui, Y., Hong, L., ... \& Hou, J. (2021). Organic photovoltaic cells with high efficiencies for both indoor and outdoor applications. Materials Chemistry Frontiers, 5(2), 893-900. 
[20] Wang, J., Yao, H., Xu, Y., Ma, L., \& Hou, J. (2021). Recent progress in reducing voltage loss in organic photovoltaic cells. Materials Chemistry Frontiers.

[21] Louis, H., Enudi, O. C., Odey, J. O., Onyebuenyi, I. B., Igbalagh, A. T., Unimuke, T. O., \& Ntui, T. N. (2021). Synthesis, characterization, DFT, and TD-DFT studies of (E)-5-((4, 6-dichloro-1, 3, 5-triazin-2-yl) amino)-4-hydroxy-3-(phenyldiazenyl) naphthalene-2, 7-diylbis (hydrogen sulfite). SN Applied Sciences, 3(7), 1-14.

[22] Louis, H., Onyebuenyi, I. B., Odey, J. O., Igbalagh, A. T., Mbonu, M. T., Eno, E. A., ... \& Offiong, O. E. (2021). Synthesis, characterization, and theoretical studies of the photovoltaic properties of novel reactive azonitrobenzaldehyde derivatives. RSC Advances, 11(45), 2843328446.

[23] Louis, H., Ifediora, L. P., Enudi, O. C., Unimuke, T. O., Asogwa, F. C., \& Moshood, Y. L. (2021). Evaluation of the excited state dynamics, photophysical properties, and the influence of donor substitution in a donor- $\pi$-acceptor system. Journal of Molecular Modeling, 27(10), 1-18.

[24] Bedoura, S., Xi, H. W., Goh, H. W., \& Lim, K. H. (2021). DFT/TDDFT Investigation on DonorAcceptor Triazole-based Copolymers for Organic Photovoltaics. Journal of Molecular Structure, 131406.

[25] Fratini, S., Nikolka, M., Salleo, A., Schweicher, G., \& Sirringhaus, H. (2020). Charge transport in high-mobility conjugated polymers and molecular semiconductors. Nature materials, 19(5), 491502.

[26] Galeotti, G., De Marchi, F., Hamzehpoor, E., MacLean, O., Rao, M. R., Chen, Y., ... \& Contini, G. (2020). Synthesis of mesoscale ordered two-dimensional $\pi$-conjugated polymers with semiconducting properties. Nature Materials, 19(8), 874-880.

[27] Chen, A. X., Kleinschmidt, A. T., Choudhary, K., \& Lipomi, D. J. (2020). Beyond stretchability: Strength, toughness, and elastic range in semiconducting polymers. Chemistry of Materials, 32(18), 7582-7601.

[28] Liu, K., Wang, L., \& Dong, R. (2020). Two-dimensional conjugated polymer films via liquidinterface-assisted synthesis toward organic electronic devices. Journal of Materials Chemistry C, 8(31), 10696-10718.

[29] O'Regan, D. D., \& Teobaldi, G. (2016). Optimization of constrained density functional theory. Physical Review B, 94(3), 035159.

[30] Ghafoor, S., BiBi, S., Kausar, A., Ali, S., Asim, S., Mansha, A., ... \& Jia, R. (2021). DFT and TDDFT Studies of Non-Fullerene Organometallic Based Acceptors for Organic Photovoltaics. Journal of Inorganic and Organometallic Polymers and Materials, 31(4), 16761687.

[31] UrRehman, S., Alam, A., Bibi, S., Sadaf, S., Khan, S. R., Shoaib, M., ... \& UrRehman, W. (2020). The effect of different aromatic conjugated bridges on optoelectronic properties of diketopyrrolopyrrole-based donor materials for organic photovoltaics. Journal of Molecular Modeling, 26, 1-16. 
[32] Martínez López, J. P., \& Solà i Puig, M. (2020). Open-Circuit Voltage of Organic Photovoltaics: A Time-Dependent and Unrestricted DFT Study in a P3HT/PCBM Complex. (C) Journal of Physical Chemistry A, 2020, vol. 124, núm. 7, p. 1300-1305.

[33] Turelli, M., Lattanzi, G., Ciofini, I., \& Adamo, C. (2021). On the Interplay between Molecular Packing and Optical Response in Thin Films for Organic Photovoltaics. The Journal of Physical Chemistry C, 125(29), 16304-16315.

[34] Zając, D., Przybylski, D., \& Sołoducho, J. (2021). Synthesis and Theoretical Investigation Using DFT of 2, 3-Diphenylquinoxaline Derivatives for Electronic and Photovoltaic Effects. Journal of Electronic Materials, 1-9.

[35] Çakal, D., Cihaner, A., \& Önal, A. M. (2020). Synthesis and electropolymerization of thieno [3, 4-c] pyrrole-4, 6-dione based donor-acceptor-donor type monomers. Journal of Electroanalytical Chemistry, 862, 114000.

[36] Çakal, D., Cihaner, A., \& Önal, A. M. (2021). Polyhedral oligomeric silsesquioxanes appended conjugated soluble polymers based on thieno [3, 4-c] pyrrole-4, 6-dione acceptor unit. Electrochimica Acta, 377, 138064.

[37] Shanmugasundaram, E., Ganesan, V., Narayanan, V., Perumalsamy, M., Kuppu, S. V., Guruviah, P. K., \& Thambusamy, S. (2021). Preparation and characterization of quantum dot doped polyaniline photoactive film for organic solar cell application. Chemical Physics Letters, 771, 138517.

[38] Gontrani, L., Cesaro, S. N., Stranges, S., Bencivenni, L., \& Pierett, A. (2014). FTIR spectra and density functional theory PED assignments of oxiranes in Ar matrix at 12 K. Spectrochimica Acta Part A: Molecular and Biomolecular Spectroscopy, 120, 558-567.

[39] Simbizi, R., Gahungu, G., \& Nguyen, M. T. (2020). Molecular structure, IR, Raman and UV-VIS spectra of 2-cyanothiophene and 3-cyanothiophene: A comparative quantum chemical investigation. Spectrochimica Acta Part A: Molecular and Biomolecular Spectroscopy, 239, 118393.

[40] Sebastian, S., \& Sundaraganesan, N. (2010). The spectroscopic (FT-IR, FT-IR gas phase, FTRaman and UV) and NBO analysis of 4-Hydroxypiperidine by density functional method. Spectrochimica Acta Part A: Molecular and Biomolecular Spectroscopy, 75(3), 941-952.

[41] El Mzioui S, Bouzzine SM, Sidir İ, Bouachrine M, Bennani MN, Bourass M, Hamidi M (2019) Theoretical investigation on $\pi$-spacer effect of the $\mathrm{D}-\pi-\mathrm{A}$ organic dyes for dye-sensitized solar cell applications: a DFT and TD-BH and H study. J Mol Model 25(4):92

[42] Tripathi A, Ganjoo A, Chetti P (2020) Influence of internal acceptor and thiophene based $\pi$ spacer in DA- $\pi$-A system on photophysical and charge transport properties for efficient DSSCs: a DFT insight. Sol Energy 209:194-205

[43] Tirado-Rives, J., \& Jorgensen, W. L. (2008). Performance of B3LYP density functional methods for a large set of organic molecules. Journal of chemical theory and computation, 4(2), 297-306.

[44] Sakr, M. A., Mohamed, A. A., Abou Kana, M. T., Elwahy, A. H., El-Daly, S. A., \& Ebeid, E. Z. M. (2021). Synthesis, characterization, DFT and TD-DFT study of novel bis (5, 6-diphenyl-1, 2, 4-triazines). Journal of Molecular Structure, 1226, 129345. 
[45] Trucks GW, Frisch MJ, Schlegel HB, Scuseria GE, Robb MA, Cheeseman JR, Scalmani G, Barone V, Mennucci B, Petersson GA, Nakatsuji H, Caricato M, Li X, Hratchian HP, Izmaylov AF, Bloino J, Zheng G, Sonnenberg JL, Hada M, Ehara M, Toyota K, Fukuda R, Hasegawa J, Ishida M, Nakajima T, Honda Y, Kitao O, Nakai H, Vreven T, Montgomery JA, Peralta Jr. JE, Ogliaro F, Bearpark M, Heyd JJ, Brothers E, Kudin KN, Staroverov VN, Kobayashi R, Normand J, Raghavachari K, Rendell A, Burant JC, Iyengar SS, Tomasi J, Cossi M, Rega N, Millam JM, Klene M, Knox JE, Cross JB, Bakken V, Adamo C, Jaramillo J, Gomperts R, Stratmann RE, Yazyev O, Austin AJ, Cammi R, Pomelli C, Ochterski JW, Martin RL, Morokuma K, Zakrzewski VG, Voth GA, Salvador P, Dannenberg JJ, Dapprich S, Daniels AD, Farkas O, Foresman JB, Ortiz JV, Cioslowskiand J, Fox DJ (2013) Gaussian09, Revision D. 01, Gaussian, Inc., Wallingford CT

[46] Lu T, Chen F (2012) Multiwfn: a multifunctional wavefunction analyzer. J Comput Chem 33(5):580-592

[47] Jamroz MH. Vibrational energy distribution analysis. Warsaw: VEDA4; 2004. p. 2004-10.

[48] Le Bahers, T., Adamo, C., \& Ciofini, I. (2011). A qualitative index of spatial extent in chargetransfer excitations. Journal of chemical theory and computation, 7(8), 2498-2506.

[49] Marcarino, M. O., Zanardi, M. M., Cicetti, S., \& Sarotti, A. M. (2020). NMR calculations with quantum methods: development of new tools for structural elucidation and beyond. Accounts of Chemical Research, 53(9), 1922-1932.

[50] Junor, G. P., Lorkowski, J., Weinstein, C. M., Jazzar, R., Pietraszuk, C., \& Bertrand, G. (2020). The Influence of C (sp3) H-Selenium Interactions on the 77Se NMR Quantification of the $\pi$ Accepting Properties of Carbenes. Angewandte Chemie International Edition, 59(49), 2202822033.

[51] Neo, W. T., Ye, Q., Chua, S. J., \& Xu, J. (2016). Conjugated polymer-based electrochromics: materials, device fabrication and application prospects. Journal of Materials Chemistry C, 4(31), 7364-7376.

[52] Ming, S., Zhen, S., Lin, K., Zhao, L., Xu, J., \& Lu, B. (2015). Thiadiazolo [3, 4-c] pyridine as an acceptor toward fast-switching green donor-acceptor-type electrochromic polymer with low bandgap. ACS applied materials \& interfaces, 7(21), 11089-11098.

[53] Kwaji, A., Adamu, H., \& Chindo, I. (2019). Isolation and characterization of Stigmasta-7, 22dien-3-ol ( $\alpha$-Spinasterol) from Entada africana stem bark crude extract. Journal of Applied and Advanced Research, 4(3), 85-88.

[54] Agwupuye, J. A., Louis, H., Enudi, O. C., Unimuke, T. O., \& Edim, M. M. (2021). Theoretical insight into electronic and molecular properties of halogenated $(\mathrm{F}, \mathrm{Cl}, \mathrm{Br})$ and hetero-atom $(\mathrm{N}, \mathrm{O}$, S) doped cyclooctane. Materials Chemistry and Physics, 125239.

[55] Wiercigroch, E., Szafraniec, E., Czamara, K., Pacia, M. Z., Majzner, K., Kochan, K., ... \& Malek, K. (2017). Raman and infrared spectroscopy of carbohydrates: A review. Spectrochimica Acta Part A: Molecular and Biomolecular Spectroscopy, 185, 317-335.

[56] Panda, B., Paul, S. C., Mohamed, N. A. N., Tay, Y. W. D., \& Tan, M. J. (2018). Measurement of tensile bond strength of 3D printed geopolymer mortar. Measurement, 113, 108-116. 
[57] Eng, J., Thompson, S., Goodwin, H., Credgington, D., \& Penfold, T. J. (2020). Competition between the heavy atom effect and vibronic coupling in donor-bridge-acceptor organometallics. Physical Chemistry Chemical Physics, 22(8), 4659-4667.

[58] Luo, J., Zhou, Y., Milner, S. T., Pantano, C. G., \& Kim, S. H. (2018). Molecular dynamics study of correlations between IR peak position and bond parameters of silica and silicate glasses: Effects of temperature and stress. Journal of the American Ceramic Society, 101(1), 178-188.

[59] Daldrop, J. O., Kappler, J., Brünig, F. N., \& Netz, R. R. (2018). Butane dihedral angle dynamics in water is dominated by internal friction. Proceedings of the National Academy of Sciences, 115(20), 5169-5174.

[60] Ying, Y., Fan, K., Luo, X., Qiao, J., \& Huang, H. (2021). Unravelling the origin of bifunctional OER/ORR activity for single-atom catalysts supported on $\mathrm{C} 2 \mathrm{~N}$ by DFT and machine learning. Journal of Materials Chemistry A, 9(31), 16860-16867.

[61] Al-Mutabagani, L. A., Alshabanah, L. A., Ahmed, H. A., \& El-Atawy, M. A. (2021). Synthesis, optical and DFT characterizations of laterally fluorinated phenyl cinnamate liquid crystal nonsymmetric system. Symmetry, 13(7), 1145.

[62] Zhang, X., Wang, J., Song, Z., \& Zhou, T. (2021). Data-Driven Ionic Liquid Design for CO2 Capture: Molecular Structure Optimization and DFT Verification. Industrial \& Engineering Chemistry Research, 60(27), 9992-10000.

[63] Enudi, O. C., Louis, H., Edim, M. M., Agwupuye, J. A., Ekpen, F. O., Bisong, E. A., \& Utsu, P. M. (2021). Understanding the aqueous chemistry of quinoline and the diazanaphthalenes: insight from DFT study. Heliyon, 7(7), e07531.

[64] Barborini, M., Sorella, S., Rontani, M., \& Corni, S. (2016). Correlation effects in scanning tunneling microscopy images of molecules revealed by quantum monte carlo. Journal of chemical theory and computation, 12(11), 5339-5349.

[65] Emamian, S., Lu, T., Kruse, H., \& Emamian, H. (2019). Exploring nature and predicting strength of hydrogen bonds: a correlation analysis between atoms-in-molecules descriptors, binding energies, and energy components of symmetry-adapted perturbation theory. Journal of computational chemistry, 40(32), 2868-2881.

[66] Tanaka, K., \& Chujo, Y. (2020). Modulation of the solid-state luminescent properties of conjugated polymers by changing the connecting points of flexible boron element blocks. Polymer Journal, 52(6), 555-566.

[67] Ko, J., Kim, Y., Kang, J. S., Berger, R., Yoon, H., \& Char, K. (2020). Enhanced Vertical Charge Transport of Homo-and Blended Semiconducting Polymers by Nanoconfinement. Advanced Materials, 32(10), 1908087.

[68] Tanaka, K., \& Chujo, Y. (2021). New idea for narrowing an energy gap by selective perturbation of one frontier molecular orbital. Chemistry Letters, 50(2), 269-279.

[69] Muz, İ., Kurban, M., \& Dalkilic, M. (2020). DFT and TD-DFT studies of new pentacene-based organic molecules as a donor material for bulk-heterojunction solar cells. Journal of Computational Electronics, 19(3), 895-904. 
[70] El Assyry, A., Lamsayah, M., Warad, I., Touzani, R., Bentiss, F., \& Zarrouk, A. (2020). Theoretical investigation using DFT of quinoxaline derivatives for electronic and photovoltaic effects. Heliyon, 6(3), e03620.

[71] Idrissi, S., Labrim, H., Bahmad, L., \& Benyoussef, A. (2021). DFT and TDDFT studies of the new inorganic perovskite CsPbI3 for solar cell applications. Chemical Physics Letters, 766, 138347.

[72] Souilah, M., Hachi, M., Fitri, A., Benjelloun, A. T., El Khattabi, S., Benzakour, M., ... \& Zgou, H. (2021). Coumarin-based D- $\pi-$ A dyes for efficient DSSCs: DFT and TD-DFT study of the $\pi$ spacers influence on photovoltaic properties. Research on Chemical Intermediates, 47(2), 875893.

[73] Nemykin, V. N., Nevonen, D. E., Ferch, L. S., Shepit, M., Herbert, D. E., \& van Lierop, J. (2021). Accurate Prediction of Mossbauer Hyperfine Parameters in Bis-Axially Coordinated Iron (II) Phthalocyanines Using Density Functional Theory Calculations: A Story of a Single Orbital Revealed by Natural Bond Orbital Analysis. Inorganic Chemistry, 60(6), 3690-3706.

[74] Golding Sheeba, G., Usha, D., Amalanathan, M., Sony Michael Mary, M., \& MarshanRobert, H. (2021). Molecular structure, vibrational spectroscopic, frontier molecular orbital and natural bond orbital analysis of anti-cancer drug 6-chloro-3-pyridine carbonitrile. Spectroscopy Letters, 54(6), 419-436. 


\section{Supplementary Files}

This is a list of supplementary files associated with this preprint. Click to download.

- Enudidad2021SI.docx 